\title{
LOS SÍMBOLOS DEL NACIONALCATOLICISMO. UNA MIRADA A TRAVÉS DE LA FOTOGRAFÍA ESCOLAR DURANTE LA DICTADURA FRANQUISTA $(1950-1959)^{\alpha}$
}

\author{
The symbols of the National-Catholicism. A look at school \\ photography during Francoism (1950-1959)
}

\section{Carlos Sanz Simón ${ }^{\beta}$}

Fecha de recepción: 07/06/2018 • Fecha de aceptación: 14/02/2019

Resumen. La dictadura de Francisco Franco trajo consigo un agresivo proceso de nacionalización especialmente palpable en la enseñanza. Liquidado el proyecto republicano, el Régimen estableció una educación basada en la exaltación de la etnicidad, la patria y la religión católica. Estos serían los pilares del autodenominado Nuevo Estado, los cuales se harían visibles explícitamente en las escuelas, dentro y fuera de ellas. El presente artículo plantea un análisis de la simbología del nacionalcatolicismo, con la intención de conocer su presencia o ausencia en función de tres ejes: la titularidad de los centros - acotada en este estudio entre religiosa y no religiosa-, su localización geográfica y la vinculación entre estos símbolos y el alumnado en función de su sexo. Para su consecución, se hace uso de las fotografías albergadas en el fondo de memorias de prácticas «Romero Marín», ubicado en el Museo/Laboratorio de Historia de la Educación «Manuel Bartolomé Cossío» de la Universidad Complutense de Madrid, y elaborado por estudiantes de la Sección de Pedagogía de la mencionada universidad. Las mismas han permitido observar algunas tendencias en función de las categorías propuestas, destacando el uso de la simbología propia en el caso de los centros religiosos en detrimento de

\footnotetext{
${ }^{\alpha}$ El presente trabajo se ha realizado gracias a la concesión de un contrato predoctoral de personal investigador en formación de la Universidad Complutense de Madrid (CT17/17-CT18/17) cofinanciado por el Banco Santander.

${ }^{\text {B }}$ Departamento de Estudios Educativos. Universidad Complutense de Madrid. C/ Rector Royo Villanova s/n, 28040 Madrid. España. csa02@ucm.es (iD http://orcid.org/0000-0002-5786-4024
}

Cómo citar este artículo: Sanz Simón, Carlos. «Los símbolos del nacionalcatolicismo. Una mirada a través de la fotografía escolar durante la dictadura franquista (1950-1959)». Historia y Memoria de la Educación 10 (2019): 409-449 
las representaciones estrictamente políticas, la aparición de símbolos propios en algunas regiones y una diferenciación explícita en la relación entre los mismos y los niños y niñas instruidos durante los años cincuenta del Régimen.

Palabras clave: Nacionalismo; Simbología; Fotografía escolar; Memorias pedagógicas; Franquismo.

Abstract. The dictatorship of Francisco Franco brought with it an aggressive process of nationalization that was especially evident in education. Having liquidated the republican project, the regime established an education based on the exaltation of ethnicity, the homeland and the Catholic religion. These would be the pillars of the self-styled New State, which would be made explicitly visible in schools, both inside and outside. This article presents an analysis of the symbology of National-Catholicism, and attempts to delve into its presence or absence in terms of three categories: the ownership of the centers -classified in this study as religious or non-religious-, their geographical location and the link between these symbols a nd the students according to their sex. In order to do so, we have used the photographs contained in the collection of the teacher-training memoirs "Romero Marin", located in the Museum/Laboratory of History of Education "Manuel Bartolomé Cossio" of the Complutense University of Madrid. They have allowed us to observe certain tendencies that relate to the proposed categories, in particular the use of the religious centers' own symbology to the detriment of strictly political representations, the appearance of some centers' own symbols in some regions and an explicit differentiation in the relationship between symbols and the boys and girls educated during the fifties.

Keywords: Nationalism; Simbology; School photography; Pedagogical Memories; Francoism.

\section{INTRODUCCIÓN}

El franquismo, como otros regímenes totalitarios europeos, hizo de la nación una exaltación. En palabras de Manuel de Puelles, «el nacionalismo considera la escuela como el instrumento por excelencia para la integración nacional y para la transmisión de valores y símbolos que constituyen ese sujeto, muchas veces hipostasiado, que es la comunidad nacional». ${ }^{1}$

\footnotetext{
${ }^{1}$ Manuel de Puelles Benítez, Política, legislación y educación (Madrid: UNED, 2017), 47-48.
} 
En el caso de la España franquista, el ideario impuesto - y transmitido en las escuelas- fue el denominado nacionalcatolicismo, caracterizado por un concepto de nación española que se reconoció en la religión y la Iglesia católica, lo cual condicionó el relato de su historia. ${ }^{2}$ Ligados a este ideario, aparecieron principios vinculados a la «cultura tradicional», basada en lo castellano, lo católico, lo rural y lo imperial al comienzo de la dictadura. ${ }^{3}$

Una de las principales vías para la exaltación del nacionalismo y la reafirmación de la identidad fue la estética. ${ }^{4}$ La simbología y los rituales en torno a ella fueron una parte imprescindible de la dictadura de Francisco Franco. En sí mismos, los símbolos patrióticos no representaron una anomalía propia del franquismo respecto a otras etapas de la historia de la educación en España. ${ }^{5}$ Sin embargo, el advenimiento de la dictadura sí supuso una intensificación en estos símbolos y prácticas, adoptando una «inundación españolista sin precedentes que, acompañada por una represión en extremo violenta, dejó pequeñas las empresas nacionalizadoras de Primo de Rivera». ${ }^{6}$

La investigación que a continuación se desarrolla pretende analizar la presencia de estos símbolos en la escuela española de los años cincuenta, con la finalidad de conocer si hubo diferencias relevantes en función de varios criterios. El primero de ellos es de carácter geográfico, haciendo hincapié en aquellas regiones que habían desarrollado previamente una identidad cultural propia —Cataluña, Galicia y el País Vasco-, en contraposición con el modelo centralista abrazado por el Régimen y que en el

\footnotetext{
2 Jordi Muñoz Mendoza, La construcción política de la identidad española: ¿del nacionalcatolicismo al patriotismo democrático? (Madrid: Centro de Investigaciones Sociológicas, 2012), 35.

${ }_{3}^{3}$ Carolyn P. Boyd, Historia Patria. Política, historia e identidad nacional en España: 1875-1975 (Barcelona: Pomares-Corredor, 1997), 208.

${ }^{4}$ Carlos Serrano, El nacimiento de Carmen. Símbolos, mitos, nación (Madrid: Taurus, 1999).

${ }_{5}$ Como así lo demuestra María del Mar del Pozo Andrés en su obra Currículum e identidad nacional. Regeneracionsimos, nacionalismos y escuela pública (1890-1939) (Madrid: Biblioteca Nueva, 2000), donde se analiza desde una perspectiva curricular la construcción de la identidad nacional, si bien se explicita en algunos momentos cómo la simbología y los rituales formaron parte del día a día de las escuelas españolas previas a la dictadura.

6 Javier Moreno Luzón y Xosé Manoel Núñez Seixas, Los colores de la patria. Símbolos nacionales en la España contemporánea (Madrid: Tecnos, 2017), 279.
} 
presente estudio se presenta bajo la figura de Castilla. ${ }^{7}$ Por otro lado, se hará hincapié en la titularidad de los centros educativos, quedando divididos en este trabajo en función de su titularidad — religiosa o no religiosa-. Finalmente, se atenderá a un análisis específico de los diferentes tipos de símbolos y se considerarán las diferencias en su aparición, de haberlas, en función del género del alumnado.

En las categorías analizadas, de forma transversal tanto la mujer como la religión tienen un papel central. Como señala Maitane Ostolaza, la historiografía reciente ha dejado de lado el estudio del catolicismo desde una perspectiva de género, bien porque la historiografía religiosa no se ha mostrado interesada en la historia social, y también por la reticencia de la historiografía profana a acercarse a la historia religiosa. Sin embargo, se considera la religión católica como un elemento a considerar dentro de las investigaciones que aborden el género y la educación para, por ejemplo, contribuir al desarrollo o refutación de teorías como la «feminización de la religión», que tanta presencia tiene en la enseñanza. ${ }^{8}$

Para su consecución se utilizarán las fotografías escolares que alberga el fondo de memorias de prácticas «Romero Marín», albergado en el Museo/Laboratorio de Historia de la Educación «Manuel Bartolomé Cossío» de la Universidad Complutense de Madrid. El uso de la fotografía cuenta con el interés de múltiples investigadores e investigadoras en el ámbito de la historia de la educación dentro y fuera de España. En 1986, la revista francesa Histoire de l'Education dedicó un número monográfico a esta fuente. Posteriormente la International Standing Conference of the History of Education abordó este aspecto en su edición de 1998, cuyas conclusiones fueron recogidas en el año 2000 por el primer volumen de la revista Paedagogica Historica, debate que continuaría en la publicación History of Education. ${ }^{9}$

\footnotetext{
${ }^{7}$ La región histórica de Castilla comprende en el presente estudio las regiones de Castilla la Vieja (provincias de Ávila, Burgos, Palencia, Santander, Segovia, Soria y Valladolid) y Castilla la Nueva (provincias de Ciudad Real, Cuenca, Guadalajara, Madrid y Toledo).

8 Maitane Ostolaza Esnal, «Género, religión y educación en la España contemporánea: Estado de la cuestión y perspectivas historiográficas», en Mujeres, hombres y catolicismo en la España contemporánea. Nuevas visiones desde la historia, ed. Inmaculada Blasco Herranz (Valencia: Tirant Humanidades, 2018), 48-68.

9 Francisca Comas Rubí, «Fotografia i història de l'educació», Educació i Història: Revista d'Història de l'Educació 15 (2010): 11-17.
} 
El interés por el estudio de la fotografía escolar apareció en España cuando la profesora María del Mar del Pozo Andrés, en 2006, publicó un artículo en la revista Historia de la Educación. Revista interuniversitaria, con el que invitó a la comunidad histórico-educativa de nuestro país a asomarse a esta fuente y su metodología. ${ }^{10}$ Desde entonces las investigaciones histórico-educativas en esta línea han seguido una trayectoria constante. La revista Educació i Història recogió en su décimo quinto número, publicado en 2010, un conjunto de investigaciones haciendo uso de esta fuente. Recientemente, en 2018, las revistas Historia y Memoria de la Educación e History of Education and Children's Literature publicaron dos números monográficos dedicados a la fotografía escolar.

Asimismo, ha sido una fuente tratada en jornadas y congresos. Destacan las XXI Jornades d'Història de l'Educació, celebradas en Palma en 2014, dedicadas al análisis y debate de las posibilidades de esta fuente histórica; y el XIX Coloquio de Historia de la Educación, celebrado en San Lorenzo de El Escorial en 2017, dedicado a los retos metodológicos actuales que presentan fuentes como los textos, los discursos y también las fotografías escolares.

\section{ESPAÑA EN EL IMAGINARIO FRANQUISTA. CASTILLA COMO EXALTACIÓN DE LA RAZA FRENTE AL RESTO DE IDENTIDADES DEL ESTADO}

El mapa de la España franquista respetó la división territorial de la Segunda República, heredado de la reforma de Javier de Burgos en 1833.11 Si bien la demarcación territorial fue similar, el mayor grado de autonomía alcanzado durante el periodo republicano, principalmente en Cataluña y País Vasco — y en menor medida en Galicia—,12 fue revocado por el

\footnotetext{
10 María del Mar del Pozo Andrés, «Imágenes e historia de la educación: construcción, reconstrucción y representación de las prácticas escolares en el aula», Historia de la Educación 25 (2006): 291-315.

11 Encargado desde el ministerio de Fomento de la organización provincial de España durante el reinado de Isabel II. El mapa que dibujó, como apunta Juan Pablo Fusi, buscó la «uniformidad provincial» y la «centralización administrativa».

12 Como señala Justo Beramendi González, Galicia sería la tercera región en aprobar su Estatuto de Autonomía, si bien lo haría desde el exilio en 1937.
} 
Régimen franquista. En la práctica, las regiones durante la dictadura no tuvieron ninguna utilidad más allá de la meramente cultural y estética. ${ }^{13}$

El franquismo optaría, por tanto, por un modelo de recentralización y por una España que se miraría en el reflejo de Castilla, evocada históricamente como corazón del reino. ${ }^{14}$ Pieza clave del origen del fascismo en España durante la Segunda República, esta región, pese a que geográficamente su delimitación ha sido difusa, ${ }^{15}$ se convirtió en el modelo de cultura y pureza que debía conformar la «raza» de hombres y mujeres de la España del franquismo. ${ }^{16}$

Al comienzo de la guerra civil, el golpe militar del bando sublevado triunfó en la vieja Castilla, entre otras zonas del país. ${ }^{17}$ En parte, los halagos y la devoción del dictador hacia esta región se debían a una cuestión de gratitud por la adscripción de esta a la causa nacional. De hecho, fue una de las primeras en las que triunfó el bando sublevado, ${ }^{18}$ algo que el dictador agradeció cuando le fue impuesta la medalla de la ciudad:

No puedo venir a Valladolid sin sentir la honda emoción de las primeras horas de nuestro Movimiento, de aquellos días en que los mozos castellanos marchaban sobre la capital y bautizaban con su

\footnotetext{
13 Xosé Manoel Núñez Seixas, «La región y lo local en el primer franquismo», en Imaginarios y representaciones de España durante el franquismo, eds. Stéphane Michonneau y Xosé M. Núñez Seixas (Madrid: Casa de Velázquez, 2014), 127-154.

${ }^{14}$ Cabe destacar que durante la Segunda República se comenzaron a fraguar varios Estatutos de Autonomía para Castilla. En 1936, como apunta Rubén Domínguez Méndez, se planteó el primero que comprendía las provincias de Castilla la Vieja y León. De forma paralela, los partidos próximos a la derecha comenzaron a plantear otro Estatuto de Castilla que comprendía las provincias de Castilla la Vieja, salvo Palencia y Valladolid, y las de Castilla la Nueva. Asimismo, durante la Guerra Civil, como recoge Luis Castro Berrojo, el franquismo emplazó su capital en la ciudad castellana de Burgos; Montserrat Guibernau, Catalan Nationalism. Francoism, transition and democracy (Londres: Routledge, 2004), 21, 43-44.

${ }_{15}$ Un ejemplo de ello es el conflicto en la delimitación entre Castilla la Vieja y León. Las provincias de Palencia y Valladolid transitaron durante años entre ambas regiones indistintamente, si bien la delimitación de 1833 - y por extensión la republicana y franquista-incluyó estas provincias en la primera.

16 José-Carlos Mainer, «La imagen de Castilla en el fascismo español», en Historia de la nación y del nacionalismo español, dirs. Antonio Morales, Juan Pablo Fusi y Andrés de Blas (Barcelona: Galaxia Gutenberg, 2013), 855-873; Boyd, Historia Patria, 208.

17 Julián Casanova Ruiz, República y guerra civil. Volumen 8 (Barcelona: Marcial Pons, 2014), 191.

${ }_{18}$ Como señala Casanova, en ciudades como la capital de Castilla la Vieja, la Guardia Civil y de Asalto se adhirieron rápidamente a los sublevados.
} 
sangre el Alto de los Leones de Castilla; aquellos momentos inolvidables en que la lealtad de estos pueblos y estas tierras campesinas les alzaban las armas para salvar a la Patria y en riada humana incontenible conquistar la victoria. ${ }^{19}$

El corazón de la España de Franco sirvió además al Régimen como matriz de héroes y heroínas del Nuevo Estado. Precisamente, los modelos principales promulgados por la dictadura fueron símbolos de Castilla: Santa Teresa de Jesús, Isabel de Castilla —o la Católica—y Santiago Apóstol. ${ }^{20}$ Mística y reina, ambas fueron dos modelos complementarios, aunando la patria y la religión. ${ }^{21}$ Junto al apóstol Santiago, se convirtieron en los patrones en los que cualquier español y española debían mirarse.

Los modelos y las etapas exaltadas por el discurso franquista responden, por tanto, a un pasado glorioso e imperial. ${ }^{22}$ Los nuevos patrones de la hispanidad reflejaban para la Dictadura a personajes valientes, abnegados y próximos a la vida asceta. Y, ante todo, provenían de Castilla.

La predilección exacerbada demostrada hacia el antiguo reino castellano se tradujo asimismo en un silenciamiento del resto de regiones que históricamente habían desarrollado una identidad propia. La centralidad que ejerció el ideal de esta región sobre el resto fue abrumadora. Sin embargo, su naturaleza excluyente se tradujo en una de las principales debilidades del esfuerzo nacionalizador del Régimen. ${ }^{23}$

El principal elemento identitario de Castilla no era otro que el idioma castellano, impuesto como la única lengua, de carácter obligatorio

\footnotetext{
19 «Discurso del Generalísimo Franco al serle ofrecida la medalla de la ciudad de Valladolid», $A B C$, 29 de octubre de 1959.

${ }^{20}$ Elena Maza Zorrilla, «El mito de Isabel de Castilla como elemento de legitimidad política en el franquismo", Historia y política 31 (2014): 169; Giuliana di Febo, La Santa de la Raza. Teresa de Ávila, un culto barroco en la España franquista (1937-1962) (Barcelona: Icaria, 1988); Javier Domínguez García, Memorias del futuro. Ideología y ficción en el símbolo de Santiago Apóstol (Madrid: Iberoamericana - Vervuert, 2008).

${ }^{21}$ Maza, «El mito de Isabel de Castilla», 175.

22 Boyd, Historia Patria, 211-212.

${ }_{23}$ Como señala Antonio Fco. Canales Serrano, esta españolización fue utilizada posteriormente por algunos nacionalismos, como el catalán, para establecer un paralelismo vencedores-españoles $v s$. derrotados-catalanes, que ha derivado en la conformación de identidades propias asentadas en la memoria de los derrotados (Antonio Francisco Canales Serrano, «El robo de la memoria. Sobre el lugar del franquismo en la historiografía católico-catalanista», Ayer 59 (2005): 259-280); José Álvarez Junco, Dioses útiles. Naciones y nacionalismos (Barcelona: Galaxia Gutenberg, 2016), 189.
} 
y nacional. Se prohibió el uso y la denominación en otro idioma que no fuera el oficial en los títulos, razones sociales, Estatutos, Reglamentos, e incluso lápidas o buques. ${ }^{24}$

Sin embargo, si bien el perfil de Castilla se mimetizó con el de España, y nutrió de ideales y modelos al resto del Estado, la identidad española evocada en el exterior vivió un cambio notable a partir de 1957, cuando el Ministerio de Información y Turismo lanzó la campaña «Spain is different», pasando de los estereotipos folclóricos de carácter local a los estereotipos asociados a la cultura andaluza, basada en el flamenco, los toros, el baile, el cante, la etnia gitana, el campo y los campesinos. ${ }^{25} \mathrm{~A}$ esa Andalucía «desprovista de su paisaje urbano, romano y barroco», pintoresca y original. ${ }^{26}$

En el ámbito educativo, habría que esperar hasta los albores de la transición democrática para atisbar un principio de cambio en la coexistencia de identidades a través de las lenguas. En aquel momento, se autorizó a los centros docentes a incluir la enseñanza de «lenguas nativas españolas» en sus programas, si bien de forma experimental y voluntaria. ${ }^{27}$

\section{IDEOLOGÍA Y SIMBOLOGÍA EN LA ESCUELA DEL PRIMER FRANQUISMO}

La instauración del franquismo conllevó una respuesta contraria a las reformas sociales y políticas de la Segunda República. Los ideólogos del pensamiento franquista siguieron defendiendo una concepción de la

\footnotetext{
${ }_{24}$ «Orden prohibiendo el uso de otro idioma que no sea el castellano en los títulos, razones sociales, Estatutos o Reglamentos y en la convocatoria y celebración de Asambleas o Juntas de las entidades que dependan de este Ministerio», Boletín Oficial del Estado (26 de mayo de 1938); «Orden por la que se prohíbe designar los buques mercantes españoles con nombres que no estén escritos en castellano», Boletín Oficial del Estado (24 de enero de 1945); Antonio Viñao Frago, Escuela para todos. Educación y modernidad en la España del siglo XX (Madrid: Marcial Pons, 2004), 185.

${ }_{25}$ Eric Storm, «Una España más española. La influencia del turismo en la imagen nacional», en Ser españoles. Imaginarios nacionalistas en el siglo XX, eds. Javier Moreno Luzón y Xosé M. Núñez Seixas (Barcelona: RBA, 2013), 543.

${ }^{26}$ José Varela Ortega, «La mirada del otro. La imagen de España en el extranjero: Introducción y esquema para la historia de un estereotipo», en Historia de la nación y del nacionalismo español, dirs. Antonio Morales Moya, Juan Pablo Fusi Aizpurúa y Andrés de Blas Guerrero (Barcelona: Galaxia Gutenberg, 2013), 1095; Álvarez Junco, Dioses útiles, 281.
}

27 Viñao, Escuela para todos. 
nacionalidad española basada en la religión católica, la historia y la cultura, si bien la influencia de la Falange tiñó este pensamiento de un aire militarizado y autoritario. ${ }^{28}$

Con el franquismo entró en auge el nacionalcatolicismo, y «lo nacional y lo católico formaron una unidad indisoluble, dando origen a una nueva identidad de ser español. Los valores "religión" y "patria" configuraron la vida política, religiosa, social y educativa de un largo periodo de nuestra historia inmediata». ${ }^{29}$ En el plano educativo, la enseñanza del Régimen desmanteló la escuela de la República y depuró al profesorado, alumnado, textos escolares e incluso bibliotecas, quedando en manos de la Iglesia hasta principios de los años cincuenta. ${ }^{30}$

El cambio sobre el planteamiento educativo franquista hizo hincapié en la diferenciación de los modelos y contribuciones que debían realizar los niños y niñas a la sociedad. A los primeros, el franquismo quiso convertirlos en individuos que debían servir a la patria a través de la esfera política, con una aportación intelectual y con una inspiración heroica, mientras las segundas contribuían, desde la esfera familiar, con una finalidad meramente reproductiva y asistencial. ${ }^{31}$

Lo que sí tuvieron en común ambos sexos en la educación franquista fue una estética escolar a través de los símbolos patrios, con la cual podían demostrar su adhesión al Régimen. ${ }^{32}$ Los frontispicios de las escuelas republicanas dejaron paso a una ornamentación diferente, marcada por la restitución del crucifijo en las aulas. Este elemento fue retirado de los centros con el advenimiento de la Segunda República, un hecho que irritó al bando sublevado y posteriormente al Régimen, como así lo refleja la propia Ley de Enseñanza Primaria de 1945.

\footnotetext{
${ }_{28}$ Boyd, Historia Patria, 207.

29 Enrique Gervilla Castillo, «La escuela del nacionalcatolicismo. Cercanía cronológica y distanciamiento axiológico», Bordón. Revista de Pedagogía 58, no. 4-5 (2006): 537-538.

30 Manuel de Puelles Benítez, Educación e ideología en la España contemporánea (Madrid: Tecnos, 2010), 291-292.

31 María del Carmen Agulló Díaz, «Mujeres para Dios, para la Patria y para el hogar», en Mujeres y educación en España. VI Coloquio de Historia de la Educación (Santiago de Compostela: Departamento de Teoría e Historia de la Educación, 1990): 19.

32 Zira Box Varela, «La fundación de un régimen. La construcción simbólica del franquismo» (Tesis doctoral, Universidad Complutense de Madrid, 2008), 282.
} 
No obstante, la cruz no fue el único elemento colgado en las aulas. Durante la Guerra Civil, entre 1936 y 1938 fueron varias las disposiciones oficiales que dibujaron el nuevo frontispicio de las aulas, encabezadas por los retratos del dictador, Francisco Franco, y del líder de la Falange, José Antonio Primo de Rivera, junto a la imagen de la Inmaculada Concepción. Juntos compondrían una suerte de altar del nacionalcatolicismo que debía estar presente en las aulas de todos los centros educativos de la España franquista. ${ }^{33}$ Asimismo, en 1938, la "Circular a la Inspección de Primera Enseñanza y Maestros Nacionales, Municipales y Privados de la España Nacional» configuraría el nuevo frontispicio, fiel reflejo de la simbiosis entre patria y religión. ${ }^{34}$

Del nuevo frontispicio destacaba el líder de la Falange. Tras su muerte, las escuelas fueron los principales emplazamientos para prolongar la memoria de José Antonio, convertido en mártir de la guerra. En 1938 se trazaron las directrices de la presencia póstuma del líder falangista. El 20 de noviembre se declaró día de luto nacional, se creó una doctrina política titulada con su nombre, que a su vez fue otorgado a nuevas instituciones educativas. Asimismo, se instauró una lección en su memoria para recordar su vida y obra. ${ }^{35} \mathrm{~A}$ partir de entonces, los símbolos de la Falange continuaron utilizándose públicamente, si bien el retrato del líder falangista fue el primero de los símbolos en desaparecer de los frontispicios, en especial de forma más acusada a partir de los años sesenta. ${ }^{36}$

En definitiva, la simbología dentro de las aulas cambió, pero también lo hicieron los símbolos nacionales. En 1936, el bando sublevado restituyó la enseña bicolor, en lo que sería el comienzo de la transformación de la simbología del Estado:

\footnotetext{
${ }_{33}$ María del Mar del Pozo Andrés y Teresa Rabazas Romero, «Imatges fotogràfiques i cultura escolar en el franquisme: una exploració de l'arxiu etnogràfic», Educació i Història: Revista d'Història de l'Educació 15 (2010): 183; Gabriel Barceló Bauzá, Francisca Comas Rubí y Bernat Sureda García, "Abriendo la caja negra: la escuela pública española de postguerra», Revista de Educación 371 (2016): 69 .

34 «Circular a la Inspección de Primera Enseñanza y Maestros Nacionales, Municipales y Privados de la España Nacional», Boletín Oficial del Estado no. 503 (8 de marzo de 1938): 6154-6156.

35 «Decreto de 17 de noviembre de 1938», Boletín Oficial del Estado: 2432; " Orden de 19 de noviembre de 1938», Boletín Oficial del Estado: 2466.

${ }^{36}$ María Pilar Queralt del Hierro, Tal como éramos. Las niñas que fuimos y... las mujeres que somos (Madrid: EDAF, 2016), s.p.
} 
Esa gloriosa enseña [la bandera bicolor] ha presidido las gestas inmortales de nuestra España; ha recibido el juramento de fidelidad de las sucesivas generaciones; ha ondeado los días de ventura y adversidad patrias, y es la que ha servido de sudario a los restos de patriotas insignes que, por los servicios prestados a su país, merecieron tal honor. ${ }^{37}$

La vuelta de la bandera roja y gualda tuvo lugar también en las instituciones educativas, y su reposición fue motivo de orgullo y nostalgia para el Régimen, aludiendo a la época imperial y relacionándola con épocas de prestigio educativo y científico en España. ${ }^{38}$

No obstante, la simbología propia del nacionalcatolicismo no implicó exclusivamente una función estética. En torno a ella se llevaron a cabo una serie de ceremonias o rituales que reforzaban el sentimiento patrio e identitario, ${ }^{39}$ de tal modo que cada día se izaba y arriaba la bandera, se rezaba y entonaban cantos. ${ }^{40}$

Las oraciones, saludos y cánticos eran comunes durante el día a día de la escuela franquista, también durante las actividades extraescolares. ${ }^{41}$ Del mismo modo, la simbología y los rituales patrióticos fueron objeto del propio contenido escolar. ${ }^{42}$

Desde su reposición, los centros educativos en la España de Franco comenzaron a incorporar el crucifijo, junto al resto de la simbología patriótica y religiosa, en los presupuestos e inventarios escolares. Generalmente,

\footnotetext{
37 «Decreto número 77», Boletín Oficial de la Junta de Defensa Nacional de España. Burgos, no. 14 (30 de agosto de 1936).

38 Orden del 27 de julio de 1939 creando en las Escuelas Nacionales, Municipales, públicas y privadas la Fiesta de la Exaltación de la Santa Cruz.

39 Agustín Escolano Benito, «Las culturas escolares en el último medio siglo», en Historia ilustrada de la escuela en España. Dos siglos de perspectiva histórica, dir. Agustín Escolano Benito (Madrid: Fundación Germán Sánchez Ruipérez, 2006): 273.

${ }^{40}$ Miguel Beas Miranda, «El orden del tiempo y los ritmos escolares», en Historia ilustrada de la escuela en España. Dos siglos de perspectiva histórica, dir. Agustín Escolano Benito (Madrid: Fundación Germán Sánchez Ruipérez, 2006): 314.

41 María Nieves Gómez García, «La infancia escolarizada: un proceso contradictorio», en Historia ilustrada de la escuela en España. Dos siglos de perspectiva histórica, dir. Agustín Escolano Benito (Madrid: Fundación Germán Sánchez Ruipérez, 2006): 336.

${ }^{42}$ En el manual Santa Tierra de España, del inspector José Muntada Bach, se puede observar la reposición del crucifijo en las aulas tras explicitar que fue "arrancado por los gobernantes ateos».
} 
estos materiales figuraban en las primeras celdas de los documentos administrativos. Sin embargo, como muestra Ramón López, la realidad de las escuelas en años de carencias muestra cómo los objetos finalmente adquiridos distaban de la voluntad inicial de los centros, con inventarios y presupuestos más modestos. ${ }^{43}$

\section{LA FOTOGRAFÍA ESCOLAR EN EL «FONDO ROMERO MARÍN». CUESTIONES METODOLÓGICAS DE UN ARCHIVO ETNOGRÁFICO}

Para el presente estudio se analizarán a través de la fotografía los símbolos patrióticos en la enseñanza primaria de los años cincuenta en España, los cuales se manifiestan con facilidad a través de la imagen. ${ }^{44}$ Se plantea un análisis iconográfico de los símbolos patrióticos y nacionalcatólicos, entendiendo estos como «aquellos significados que los profesores y alumnos adjudican a diferentes objetos, funciones o procesos dentro de la escuela». ${ }^{45}$ En el caso concreto de esta investigación, se hace referencia a los objetos que reflejan un modelo de identidad nacional y que refuerzan el proceso de nacionalización en las aulas. Tal y como se ha expuesto anteriormente, los elementos oficiales debían ser un crucifijo, una imagen de la Inmaculada y los retratos de Francisco Franco y José Antonio Primo de Rivera. Junto a ellos, de cara a este análisis se añaden tres elementos más: banderas, heráldica y mapas, por ser elementos que proyectan la imagen de un país y que refuerzan la identidad nacional en el aula. Finalmente, y tras el análisis de las fotografías, se contempla una última categoría que recoge elementos folclóricos.

Los ejemplares de las memorias fueron seleccionados en función de tres criterios. El primero de ellos, que los tomos contuvieran fotografías. El segundo, que estuvieran redactadas en cursos académicos correspondientes a los años cincuenta. Y, finalmente, que pertenecieran a las regiones elegidas, esto es, Castilla, Cataluña, Galicia y País Vasco.

\footnotetext{
${ }^{43}$ Ramón López Martín, «El utillaje escolar en la segunda mitad del siglo XX», en Historia ilustrada de la escuela en España. Dos siglos de perspectiva histórica, dir. Agustín Escolano Benito (Madrid: Fundación Germán Sánchez Ruipérez, 2006): 432.

${ }_{44}$ Peter Burke, Visto y no visto: el uso de la imagen como documento histórico (Barcelona: Crítica, 2005), 82.

45 María del Mar del Pozo Andrés y Teresa Rabazas Romero, «Las imágenes fotográficas como fuente para el estudio de la cultura escolar: precisiones conceptuales y metodológicas», Revista de Ciencias de la Educación: Órgano del Instituto Calasanz de Ciencias de la Educación 231-232 (2012): 405.
} 
El fondo de memorias de prácticas «Romero Marín»se trata de un acervo de 891 ejemplares, que recogen las experiencias de las prácticas de estudiantes de primer curso de Pedagogía de la Facultad de Filosofía y Letras de la Universidad Complutense de Madrid desde 1950 a 1973. Se encuentra ubicado en el Museo/Laboratorio de Historia de la Educación «Manuel Bartolomé Cossío» de la mencionada universidad, el cual desde 1991 custodia varias colecciones bibliográficas y patrimoniales del ámbito histórico educativo. ${ }^{46}$

La colección de memorias de prácticas recibe su nombre del profesor Anselmo Romero Marín, encargado de materias como Principios de Metodología y Pedagogía general y pedagogía racional desde 1947, y nombrado catedrático de esta última disciplina de la mencionada facultad madrileña en 1949.47 Junto a Víctor García Hoz, se podría considerar a Romero Marín como un actor «determinante en la configuración del campo de la pedagogía y de la didáctica superiores».48 Asimismo, se encargaría también desde su cátedra de dirigir las prácticas pedagógicas hasta entrados los años setenta, dando lugar a casi novecientos trabajos inéditos del alumnado de Pedagogía de la Universidad Complutense. ${ }^{49}$

Las memorias del «Fondo Romero Marín» eran el resultado de un periodo en el que el alumnado observaba con detalle una realidad pedagógica de diversa índole:

Las memorias de las prácticas pedagógicas que realizaron los y las estudiantes de Pedagogía consistían en una disertación escrita en el que se realizaban una serie de anotaciones que tenían (en la mayoría de los casos) una cierta vocación narrativa, aspirando a construir un relato sobre un aspecto concreto de la realidad educativa.

\footnotetext{
46 Pozo y Rabazas, «Imatges fotogràfiques», 165-194; Teresa Rabazas Romero y Sara Ramos Zamora, «Museografía y docencia en el Museo/Laboratorio de Historia de la Educación Manuel Bartolomé Cossío», en Los Museos Pedagógicos de España. Entre la memoria y la creatividad, coord. Pablo Álvarez Domínguez (Sevilla-Gijón: Ediciones de la Universidad de Sevilla-Trea Ediciones, 2016), 163-172.

47 Julio Ruiz Berrio, «Manuel Bartolomé Cossío y los comienzos de los estudios de Pedagogía en la Universidad», en Pedagogía y Educación ante el siglo XXI, ed. Julio Ruiz Berrio (Madrid: Departamento de Teoría e Historia de la Educación, 2005), 117-141.

48 Juan Mainer Baqué, La forja de un campo profesional. Pedagogía y Didáctica de las Ciencias Sociales en España (1900-1970) (Madrid: Consejo Superior de Investigaciones Científicas, 2009 ), 543.

49 Rabazas y Ramos, «Museografía y docencia en el Museo/Laboratorio», 169.
} 
Cada estudiante (solo o junto a otras personas) tenía que elaborar un trabajo monográfico que describiese, de la forma más completa y objetiva posible, una realidad escolar. ${ }^{50}$

En concreto, el trabajo debía dividirse en dos partes, una teórica y otra práctica. En la primera, se realizaba una descripción de la experiencia escolar observada por el estudiante. En la segunda se realizaba un análisis práctico e interpretativo con una valoración final, incluyendo propuestas de mejora. ${ }^{51}$ Cabe destacar que la labor realizada por los estudiantes encerraba una gran complejidad por varias razones: debían buscar una experiencia escolar, acudir a ella e integrarse y analizarla de forma crítica durante un año; en algunos casos hacían fotografías, probablemente por la insistencia de Romero Marín de incluirlas junto a ilustraciones, postales, cuadros artísticos y también símbolos religiosos y patrióticos entre otros. ${ }^{52}$

Sin embargo, hemos de considerar que este fondo documental era realizado por alumnado que generalmente era ajeno a las realidades educativas que observaba y analizaba, si bien en algunos casos sí tenía un estrecho vínculo con los centros y aulas descritas, ${ }^{53}$ por lo que la imagen que de estas instituciones proyectaba podría estar condicionada.

Con la colección fotográfica de las memorias se han realizado hasta la fecha numerosos trabajos de diversas temáticas, que podrían agruparse en el análisis sobre la enseñanza franquista en función de zonas geográficas, etapas e instituciones educativas, modelos pedagógicos y estudios generales sobre el archivo y la visión global de la educación de las primeras generaciones de pedagogos..$^{54}$

\footnotetext{
50 María Poveda Sanz y Teresa Rabazas Romero, «El Fondo Romero Marín del Museo "Manuel B. Cossío”. Análisis de las memorias de las prácticas de Pedagogía», en III Foro Ibérico de Museísmo Pedagógico y V Jornadas Científicas de la Sociedad Española para el Estudio del Patrimonio Histórico Educativo, (2012): 329. URL: http://congresos.um.es/fimupesephe/fimupesephe2012/schedConf/presentations.

51 Pozo y Rabazas, «Imatges fotogràfiques», 177. Castellano: «La primera consistía en una descripción objetiva, eminentemente teórica, de la experiencia escolar elegida por el estudiante; la segunda, de carácter práctico, se entendía como un análisis e interpretación de los datos y una valoración crítica final, con propuestas de mejora» (Traducción del autor).

52 Pozo y Rabazas, «Imatges fotogràfiques», 177-178.

53 Pozo y Rabazas, «Imatges fotogràfiques», 179.

54 Sirvan como muestra los siguientes trabajos: Teresa Rabazas Romero, Sara Ramos Zamora y Carmen Colmenar Orzaes, «Fotografía y representación de la escuela privada madrileña en el
} 
En la actualidad el Fondo «Romero Marín» ofrece líneas de investigación futuras de diversa naturaleza por la heterogeneidad del contenido y fuentes que ofrece. Aspectos como los tiempos y espacios escolares, o el análisis de los diferentes agentes sociales que históricamente han interactuado con la escuela son algunas de ellas.

\section{ICONOLOGÍA DE LA SIMBOLOGÍA PATRIÓTICA DE LOS AÑOS CINCUENTA (1950-1959)}

\section{Consideraciones descriptivas}

Inicialmente, y a modo de análisis descriptivo, de las 891 memorias que componen el fondo, para la presente investigación se han consultado un total de 89 ejemplares, correspondientes a las regiones objeto de estudio - Castilla, Cataluña, Galicia y País Vasco- entre los años 1950 y 1959. En total, esta muestra cuenta con 982 fotografías, 361 recortes y 113 postales. Tras su cotejamiento, se seleccionaron aquellas que guardaban relación con las categorías fijadas, quedando finalmente un total de 53 memorias, las cuales contenían 108 fotografías, 35 recortes y 12 postales. En síntesis, sobre el total de imágenes sujetas a los criterios de este estudio, la cantidad de ellas que coincide con alguna categoría de análisis representa algo más de la décima parte.

Si atendemos a la distribución de fotografías, recortes y postales en función de la titularidad de los centros, se observa que, si bien respecto al conjunto la cantidad total es ligeramente superior en centros de titularidad religiosa, la proporción de los tipos de fuentes gráficas en función de ambos tipos de centro difiere considerablemente (gráfico 1). Esto podría deberse a que los centros gestionados por órdenes y congregaciones religiosas, generalmente privados, han arrastrado históricamente una cultura de «márketing escolar» que los ha llevado a editar

\footnotetext{
franquismo. Entre la propaganda y el relato», Historia y memoria de la educación 8 (2018): 397-448; Teresa Rabazas Romero y Sara Ramos Zamora, «The school child. Two images of a pedagogical model in Madrid, 1960s», History of Education \& Children's Literature 8, no. 1 (2018): 305-326; Miriam Sonlleva Velasco, Carlos Sanz Simón y Luis Mariano Torrego Egido, «Sociedad y educación en la posguerra (1939-1953). Una mirada desde las imágenes de las memorias de prácticas de los primeros pedagogos instruidos en el franquismo», Historia Social y de la Educación 7, no. 1 (2018): 26-54; Pozo y Rabazas, «Imatges fotografiques».
} 
material visual propio para divulgar sus ideales pedagógicos e incrementar la matriculación en sus centros.

Gráfico 1. Distribución de los tipos de fuentes gráficas en función de la titularidad de los centros

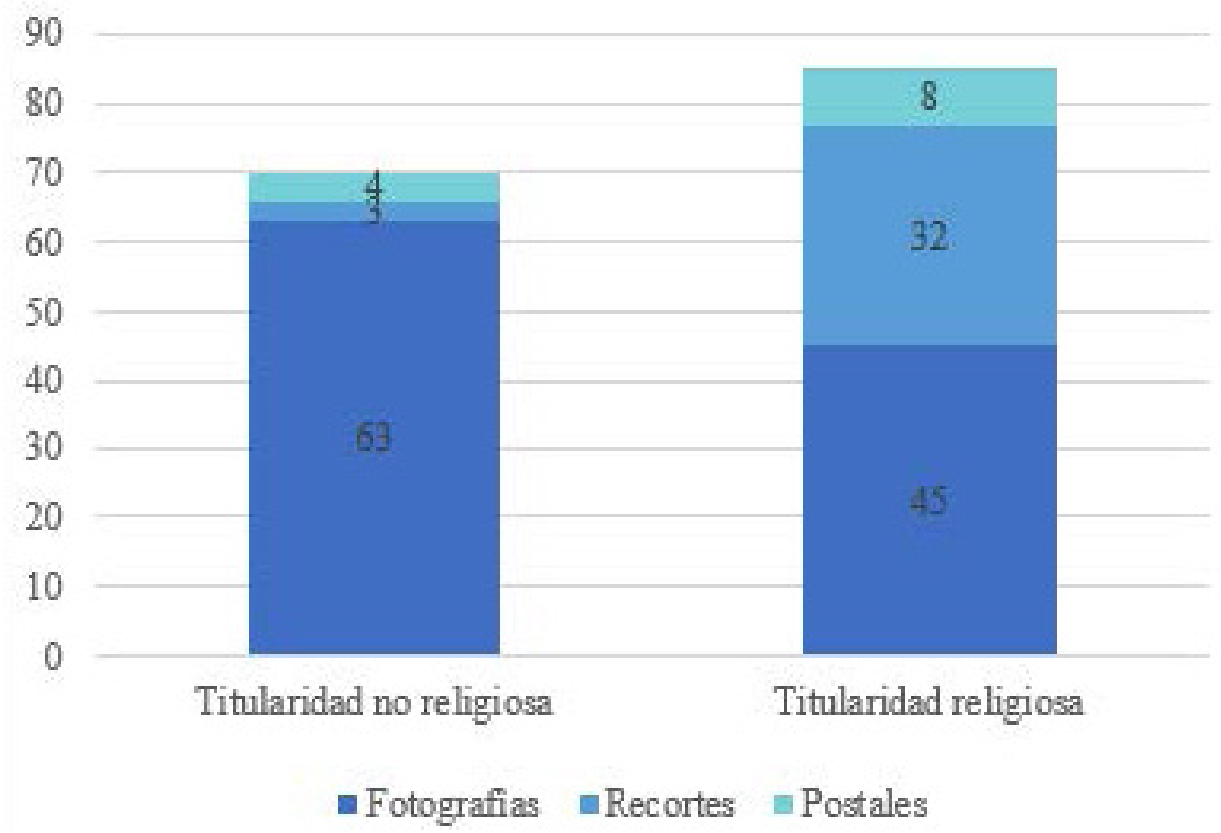

Fuente: elaboración propia.

Desde una perspectiva geográfica, la región de Castilla acumula la mayor parte de la muestra, con 79 fotografías, 28 recortes y 12 postales. Seguidamente se encuentra el País Vasco, con 13 fotografías y cinco recortes; Galicia con 12 fotografías y un recorte; y Cataluña, con cuatro fotografías y un recorte. ${ }^{55}$

Finalmente, cabe destacar que, del total de las imágenes, en la mitad de ellas se muestran espacios escolares vacíos. Esto podría deberse a la incapacidad del alumnado en prácticas - y, en su caso, del fotógrafo/a profesional- de realizar fotografías durante las clases por causas

\footnotetext{
${ }^{55}$ La acusada asimetría en la distribución se debe a la ubicación de la universidad, motivo por el cual la diáspora de las memorias se encuentra concentrada en torno a la provincia de Madrid y sus limítrofes, que acaparan casi el 70\% de las fotografías, recortes y postales sólo de Castilla.
} 
estéticas o reticencias del centro y del profesorado. Este tipo de imágenes es más frecuente en los centros religiosos, alcanzando un $60 \%$ del total.

\section{Análisis iconográfico}

De acuerdo con la gestión de los centros, la región y el sexo del alumnado, se desarrolla un análisis iconográfico de cada categoría.

\section{Titularidad de los centros de enseñanza}

En función de si los centros eran gestionados por congregaciones religiosas o no, se desglosa la frecuencia con la que aparecen los símbolos nacionalcatólicos (ver gráfico 2). En aquellos centros cuya titularidad no es religiosa, la representación de la simbología es considerablemente heterogénea, destacando la simbología religiosa, los retratos y las banderas. En menor medida aparecen los escudos, los mapas y otros símbolos, de carácter regional y folclórico, que en un principio no se habían contemplado y que tras su aparición en las imágenes han sido incorporados como otra categoría.

Gráfico 2. Distribución de la simbología nacionalcatólica en función de la titularidad de los centros

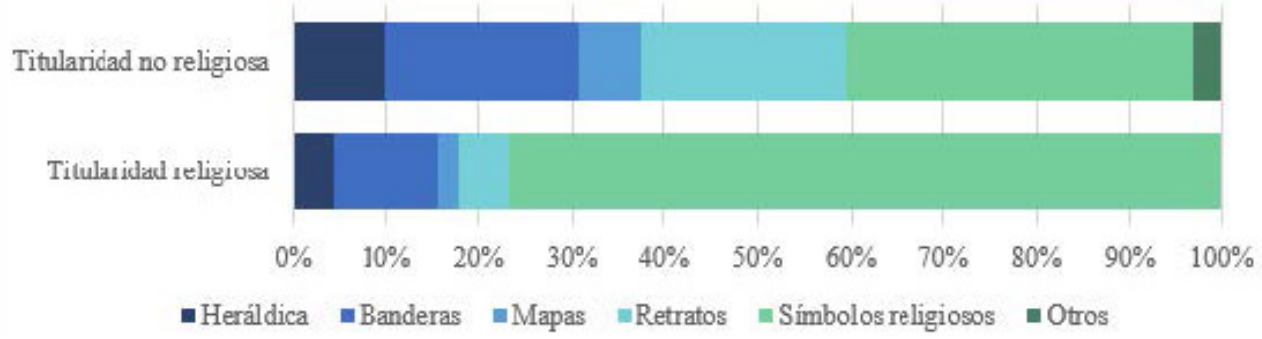

Fuente: elaboración propia.

Sin embargo, en aquellos centros que sí dependen de la Iglesia católica, la simbología religiosa está mucho más presente, copando más del $75 \%$ de los símbolos que aparecen en las imágenes. De esta forma, las banderas, los retratos, los escudos y los mapas registran frecuencias claramente inferiores, máxime en comparación con los centros de titularidad no religiosa. 
Para el análisis de esta categoría, se han fijado tres espacios o niveles de los centros escolares (ver gráfico 3): las aulas, otras dependencias (bibliotecas, comedores, salas de exposiciones, capillas...) y exteriores (donde en el análisis se distingue entre la fachada y las actividades escolares realizadas fuera de los centros).

Gráfico 3. Distribución de la simbología patriótica y religiosa en los diferentes espacios de los centros en función de la titularidad

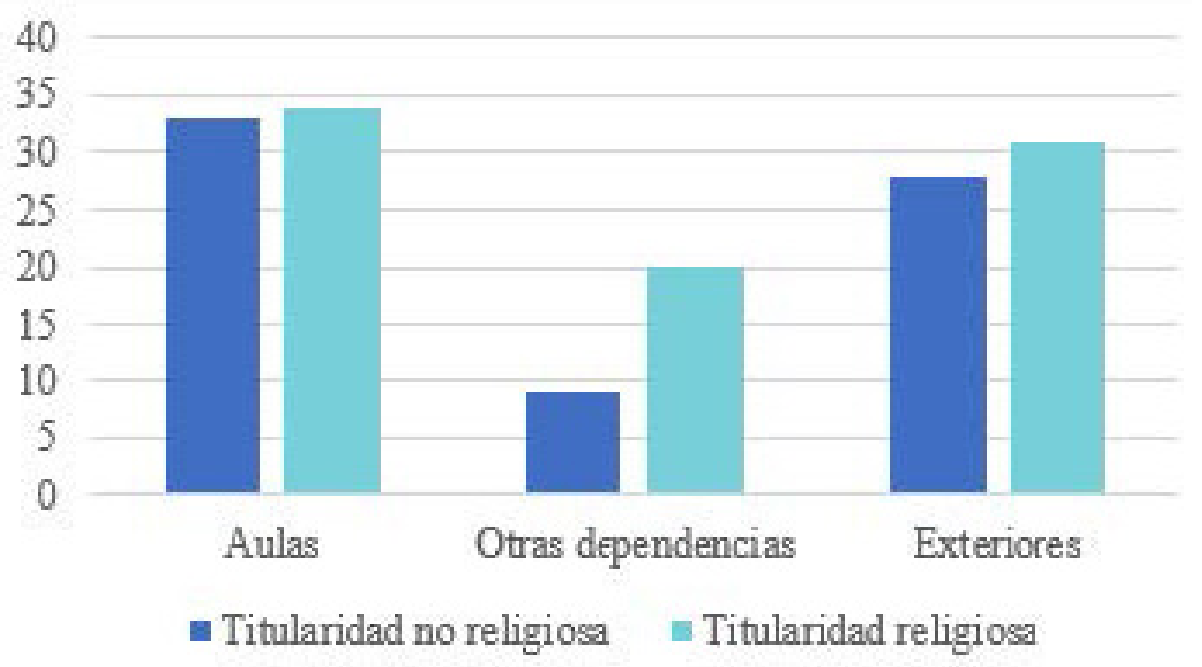

Fuente: elaboración propia.

En el caso de los centros cuya gestión no era religiosa, la simbología se representa en la mayoría de los casos en el interior del aula, con un frontispicio característico en el que los símbolos religiosos (crucifijo y retrato de la Inmaculada Concepción) se combinan en la mayoría de los casos con el retrato del jefe del Estado (fotografía 1). Otros frontispicios encontrados ubican únicamente el retrato de la Inmaculada Concepción o simbología religiosa (pequeñas estatuas del Sagrado Corazón o de vírgenes). Considerando separadamente cada símbolo, el más frecuente en las aulas de estas escuelas, es el crucifijo (55\%), seguido del retrato del dictador y de la Inmaculada Concepción (48\%), estatuas y otros retratos religiosos (33\%), el retrato de José Antonio Primo de Rivera (18\%), mapas de Europa, nacionales y regional (12\%) y la bandera nacional (3\%). En el caso del líder de la Falange, cuando aparece, lo 
hace en la mayoría de los casos bajo la presencia del retrato del dictador, y en una ocasión ha aparecido con la Inmaculada Concepción o en solitario (fotografía 2).
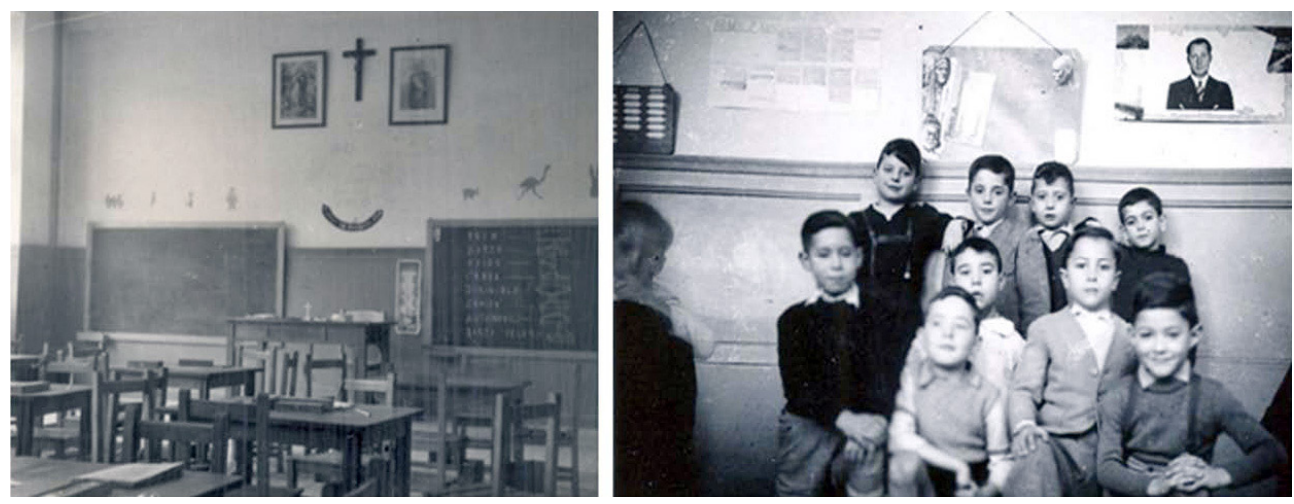

Fotografía 1. Frontispicio con el crucifijo y los retratos de Francisco Franco y la Inmaculada Concepción (San Sebastián, 1958). ${ }^{56}$

Fotografía 2. Aula decorada con una fotografía del líder de la Falange (Madrid, 1957). ${ }^{57}$

Otros espacios del interior de los centros destacan por la simbología religiosa, en el caso de lugares como la capilla, la biblioteca o el comedor (55\%). En estos dos últimos lugares también estuvieron presentes el retrato de José Antonio y algunos mapas (22\% cada uno), símbolos que también estuvieron presentes en exposiciones junto a retratos oficiales y banderas (11\%).

Los exteriores de la escuela fueron también espacios donde la simbología, sobre todo nacional y fascista estuvo presente. Los símbolos patrióticos predominaban en las fachadas de los centros, donde habitualmente se ubicaban los mástiles y banderas nacionales $(74 \%),{ }^{58}$ y los

\footnotetext{
${ }_{56}$ María del Carmen Mezquita Mendizábal, «El problema de la inmigración en relación con la vida escolar de San Sebastián», 1958, pp. 82, 367, Fondo Romero Marín (FRM), Museo de Historia de la Educación Manuel Bartolomé Cossío, UCM.

57 Orencio Sánchez Manzano , «La enseñanza en los internados y grupos escolares municipales», 1957, pp. 60, 122, Fondo Romero Marín (FRM, Museo de Historia de la Educación Manuel Bartolomé Cossío, UCM.

58 Durante la jornada escolar se izaba y arriaba la bandera al inicio y al final de esta, motivo por el cual en algunas imágenes aparecen captados solamente los mástiles, en momentos en los que no hay actividad en los centros. La proporción de mástiles con y sin bandera en las fachadas es similar, y su
} 
escudos (42\%). En el caso de la heráldica, se distribuía entre la nacional y la local, e incluso regional, si bien la definición de las fotografías no ha permitido realizar una distinción clara en todos los casos.

En el exterior de las escuelas la Falange vería representada la simbología y los rituales del fascismo. Carteles, monumentos, ceremonias y actividades (44\%) harían de los espacios abiertos de las escuelas su principal emplazamiento, lo que contrasta con la simbología encontrada dentro de las mismas. Estas actividades eran habitualmente celebraciones por la inauguración de centros, recepción de autoridades, saludos o actividades físicas. Además, también tuvieron lugar eventos culturales con elementos regionales como vestidos o instrumentos musicales (fotografía 3).

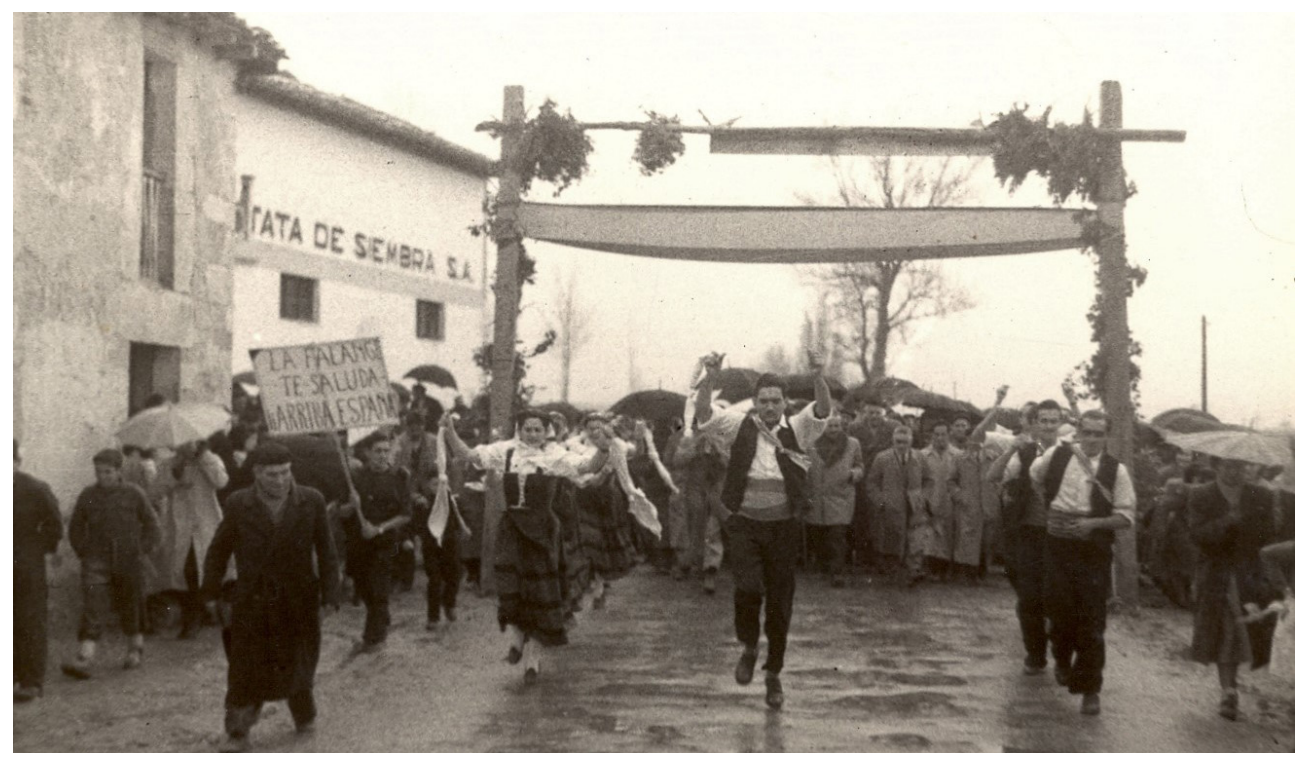

Fotografía 3. Recepción de autoridades en el municipio de Aforados de Moneo

(Burgos, 1951)..$^{59}$

distribución geográfica no permite extraer una interpretación de oposición a los símbolos nacionales.

59 María Inmaculada López Marañón, «Los problemas de la educación en Aforados de Moneo», 1952, pp. 26, 736, Fondo Romero Marín (FRM). 
Respecto a los centros cuya titularidad sí era religiosa, la simbología católica y propia, como se ha señalado anteriormente, tuvo una presencia prácticamente hegemónica dentro y fuera de las aulas. En su interior, las imágenes muestran la predominancia de los símbolos propios (91\%), con retratos y esculturas de santos, vírgenes, crucifijos y escenas religiosas (fotografía 4). Otros símbolos característicos que formaron parte de las aulas de estos centros fueron el retrato del jefe del Estado $(15 \%)$, mapas nacionales (12\%), banderas nacionales $(9 \%)$, el escudo nacional y el retrato del líder de la Falange (3\%). La simbología nacional en las aulas de centros religiosos registra una aparición considerablemente más discreta que en los centros cuya titularidad no pertenecía a la Iglesia católica.

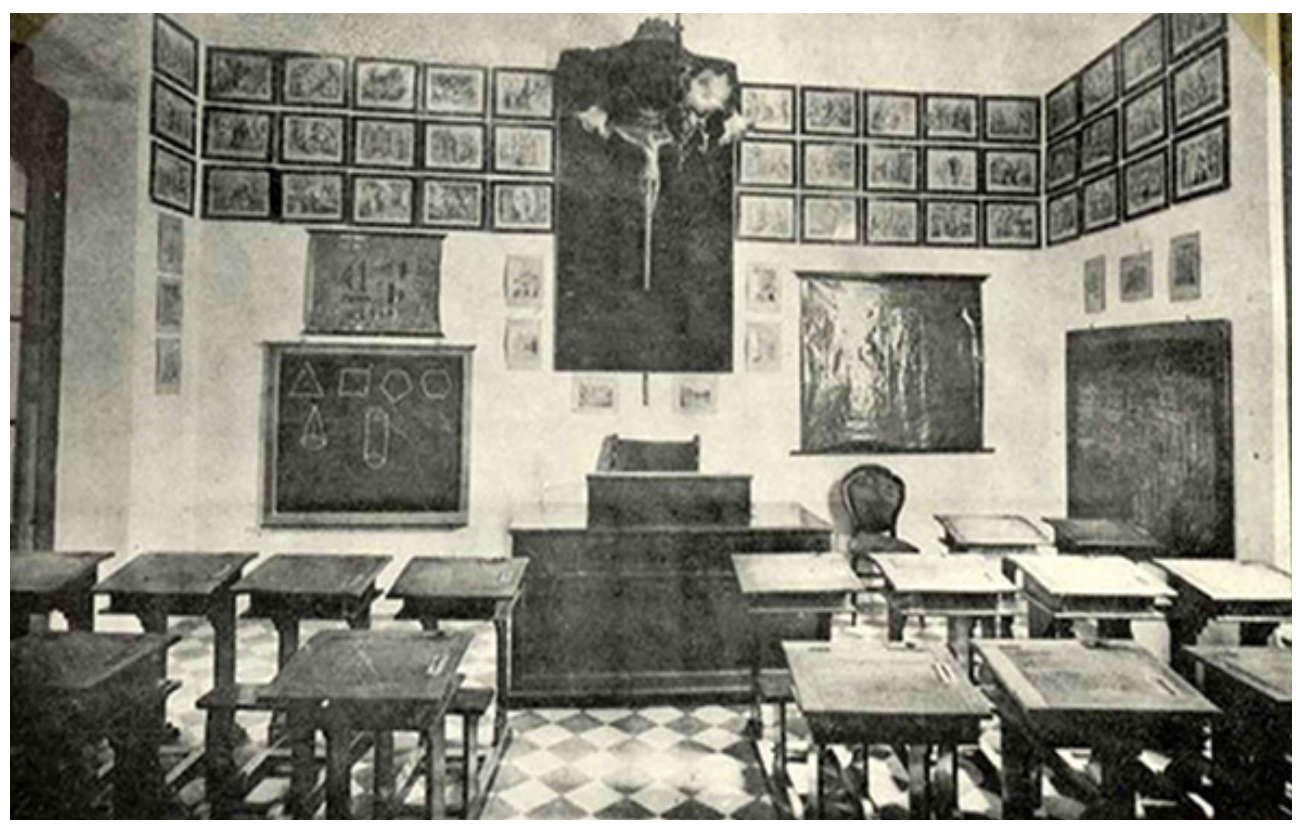

Fotografía 4. Clase de primera enseñanza del Real Colegio de Nuestra Señora de los Remedios en Toledo (1959). 60

${ }_{60}$ María Ángeles Laín Carrasco, «El colegio Nuestra Señora de los Remedios para doncellas nobles», 1959, s.p., 346, Fondo Romero Marín (FRM), Museo de Historia de la Educación Manuel Bartolomé Cossío, UCM. 
Fuera de las aulas, en otros espacios de los centros, la plena totalidad de la simbología es de carácter religioso, con objetos similares a los encontrados en las aulas. La mayoría de las imágenes que corresponden a esta categoría pertenecen a capillas, aunque esta simbología también estaba presente en comedores, bibliotecas y salones de actos. De forma anecdótica se han registrado un retrato del jefe del Estado, y un conjunto de seis banderas nacionales junto al escudo de una congregación religiosa presidiendo un salón de actos (fotografía 5).

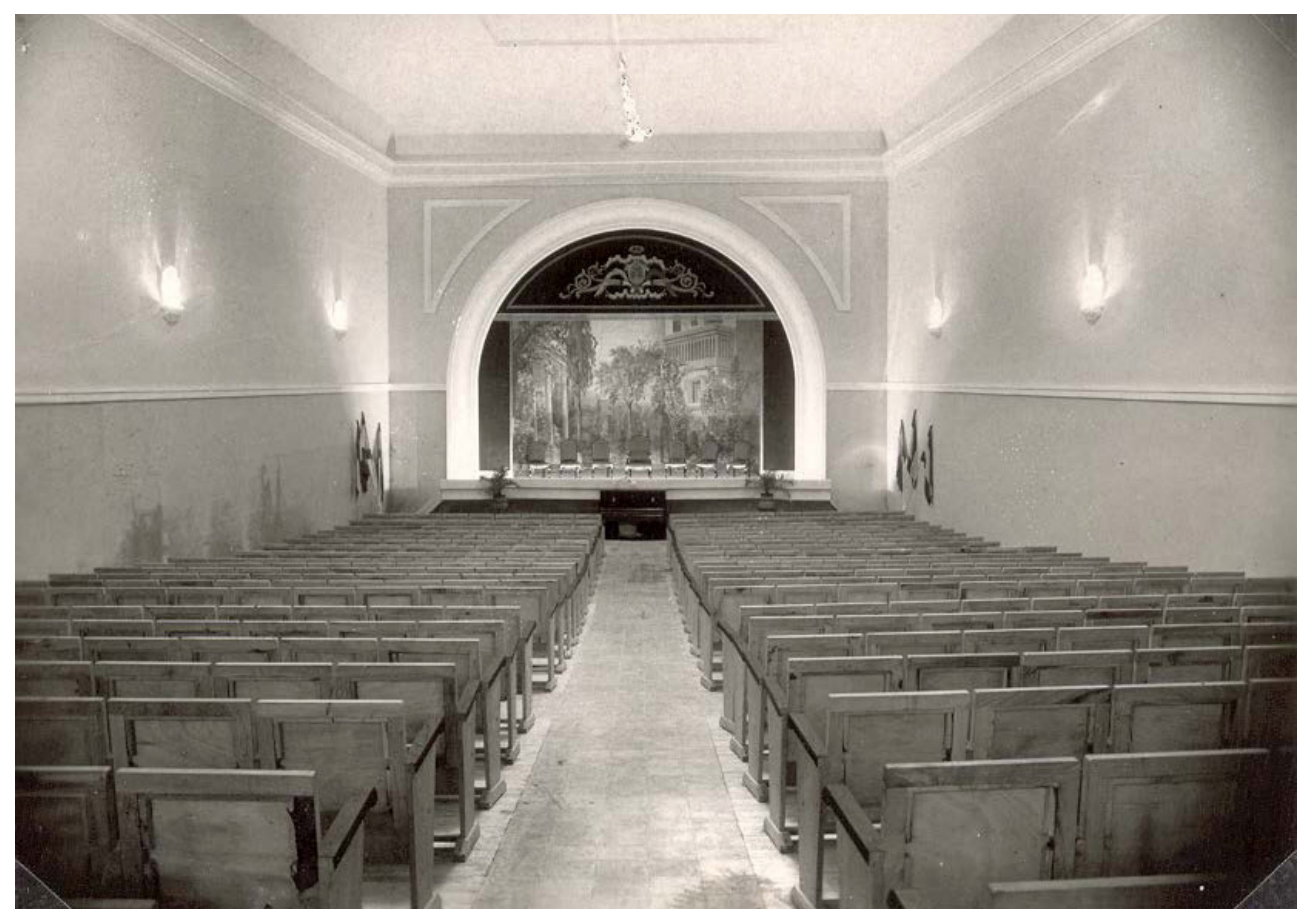

Fotografía 5. Salón de actos del colegio de los padres Escolapios en Getafe (1950). ${ }^{61}$

En lo relativo a los exteriores, a diferencia de los centros de titularidad no religiosa, los centros católicos presentan una estética en sus fachadas que alterna los símbolos nacionales con los de culto (50\%).

${ }^{61}$ Cesárea Eloísa Pleite Laín, «La enseñanza en Getafe (Madrid)», 1950, pp. 30, 739, Fondo Romero Marín (FRM). 
Asimismo, los patios y alrededores de las escuelas están copados por esta simbología, que queda representada fundamentalmente en forma de estatuas y relieves (fotografía 6).

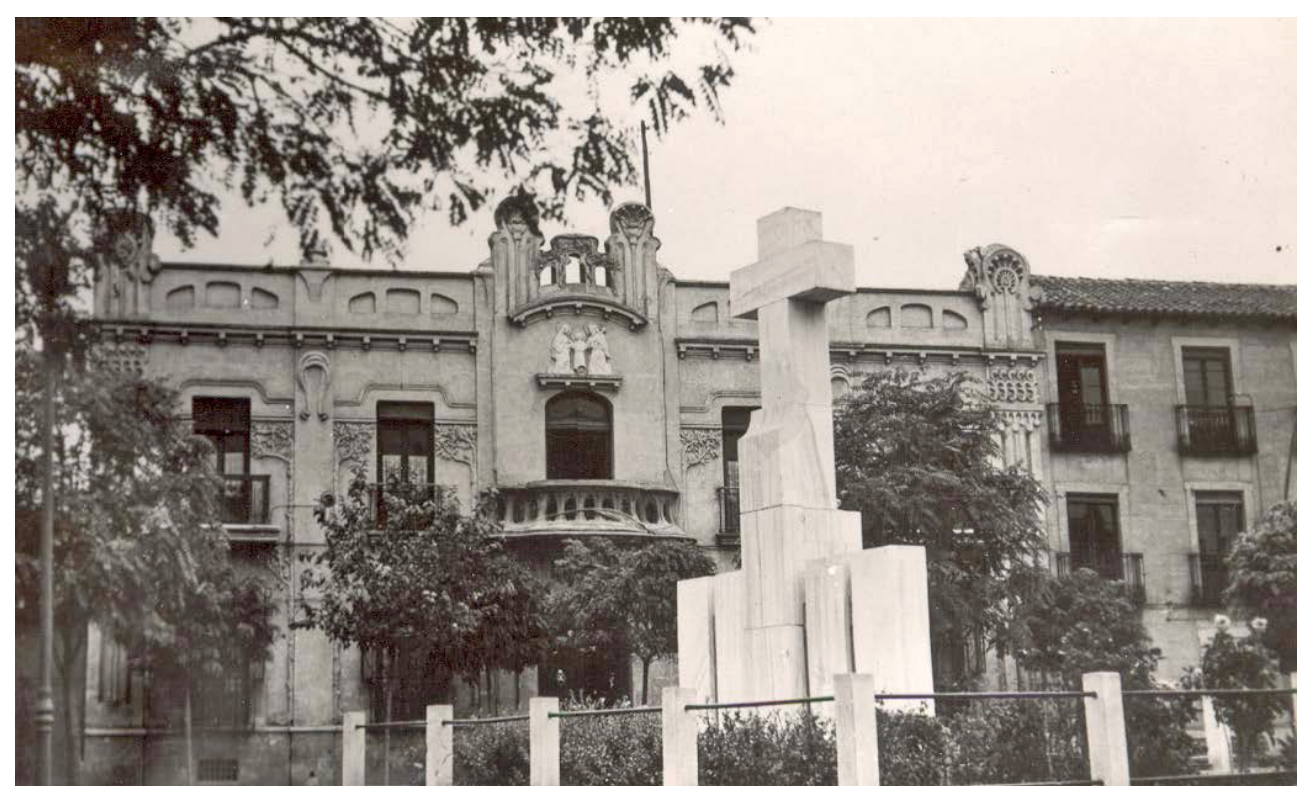

Fotografía 6. Escultura de una cruz frente a un centro religioso en cuyo frontón se representa a la Sagrada Familia, en Alcázar de San Juan

(Ciudad Real, 1956). ${ }^{62}$

Las actividades realizadas fuera del recinto escolar tenían una clara vocación católica en estos centros. Procesiones, comuniones y romerías eran algunos de los principales eventos escolares y sociales donde la simbología aparecía en la vestimenta, utensilios e incluso decorando edificios y calles (fotografía 7).

62 Juliana Serrano Vaquero, «Monografía cultural de Alcázar de San Juan (Ciudad Real)», 1956, pp. 42b, 482, Fondo Romero Marín (FRM), Museo de Historia de la Educación Manuel Bartolomé Cossío, UCM. 


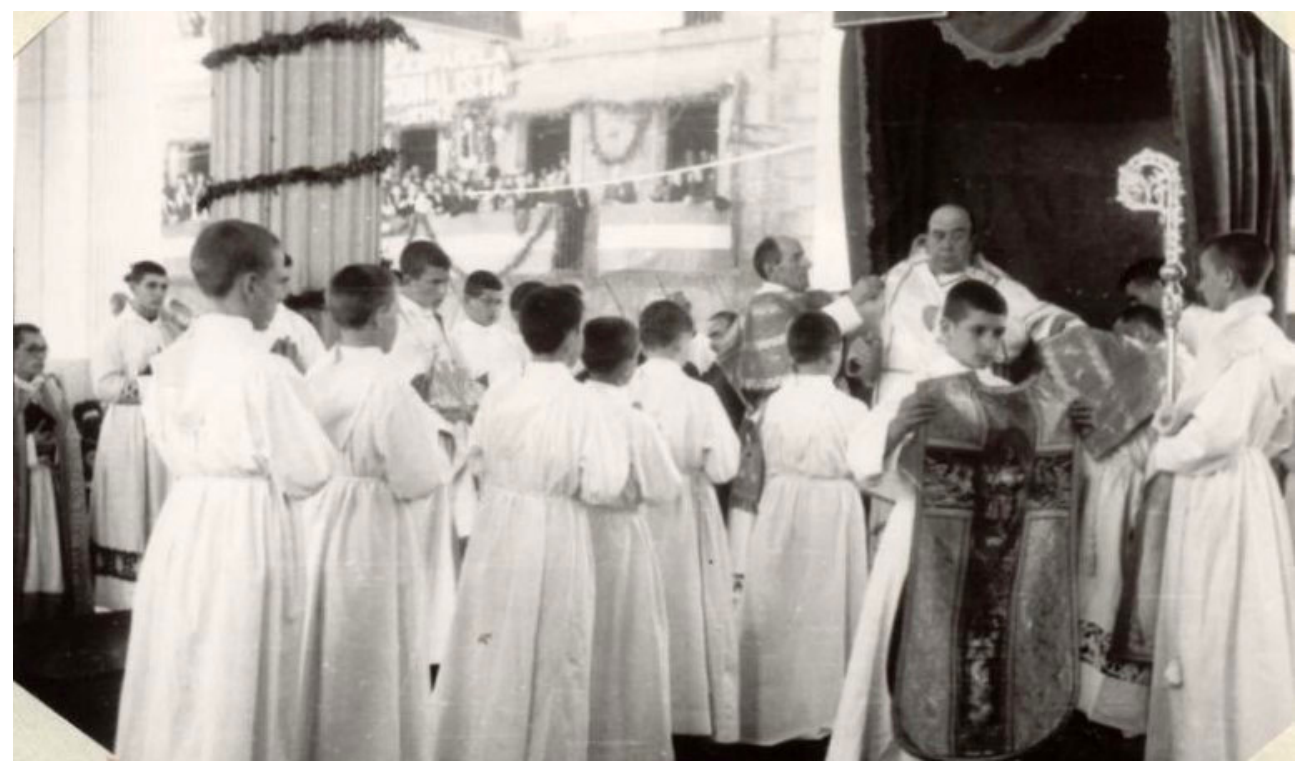

Fotografía 7. Preparación de una procesión en la escuela de los padres benedictinos en Lazcano (Guipúzcoa, 1959).63

En definitiva, estos centros no tuvieron una representación de la simbología nacional tan heterogénea como las escuelas no gestionadas por la Iglesia, marcando así las distancias con ellas y anteponiendo la identidad religiosa e institucional a la nacional.

\section{Distribución geográfica}

Atendiendo a las regiones seleccionadas, y al igual que ocurriera en el análisis en función del tipo de centro, la simbología religiosa fue, en líneas generales, la más frecuente en los centros analizados (gráfico 4). Seguidamente se encuentran las banderas, los retratos, la heráldica, los mapas y la categoría que incluye algunos elementos regionales no recogidos en el resto de los grupos, y denominado como «Otros».

\footnotetext{
${ }^{63}$ Honorato Zubiri Grate, «La realidad educativa en el colegio de segunda enseñanza de los padres benedictinos de Lazcano», 1959, pp. 75, 83, Fondo Romero Marín (FRM), Museo de Historia de la Educación Manuel Bartolomé Cossío, UCM.
} 
Gráfico 4. Representación de la simbología patriótica y religiosa en función de las regiones

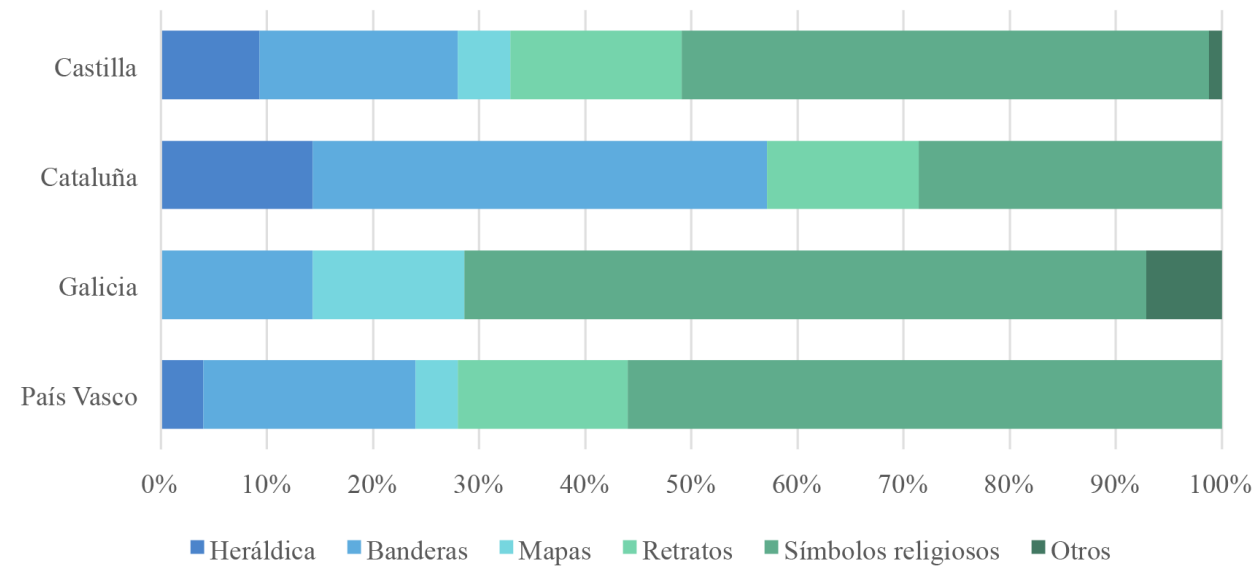

Fuente: elaboración propia.

Los elementos diferenciales que han aparecido en las imágenes de las regiones seleccionadas están representados principalmente en los mapas, y en menor medida en las actividades culturales y la heráldica.

Los mapas son objetos cuya finalidad es clasificadora, ${ }^{64}$ y que desde el siglo XX se convirtieron en una suerte de logotipo, «formando un poderoso emblema de los nacionalismos». ${ }^{65}$ Para el historiador John Harley, estos poseen una identidad topográfica y significados simbólicos, y avanza hacia el concepto de la ideología del espacio. ${ }^{66}$

En el marco del presente estudio, son objetos que se dan con la misma frecuencia en ambos tipos de centro, si bien en aquellos que son religiosos aparecen en la mayoría de los casos mapas físicos del mundo, de algunos continentes (África, América del Sur y Europa) y nacionales (fotografía 8).

\footnotetext{
${ }^{64}$ Benedict Anderson, Comunidades imaginadas. Reflexiones sobre el origen y la difusión del nacionalismo (México D. F.: Fondo de Cultura Económica, 1993), 241.

65 Anderson, Comunidades imaginadas, 245.

${ }^{66}$ John Brian Harley, The new nature of maps: essays in the history of cartography (Baltimore: The John Hopkins University Press, 2001), 48.
} 


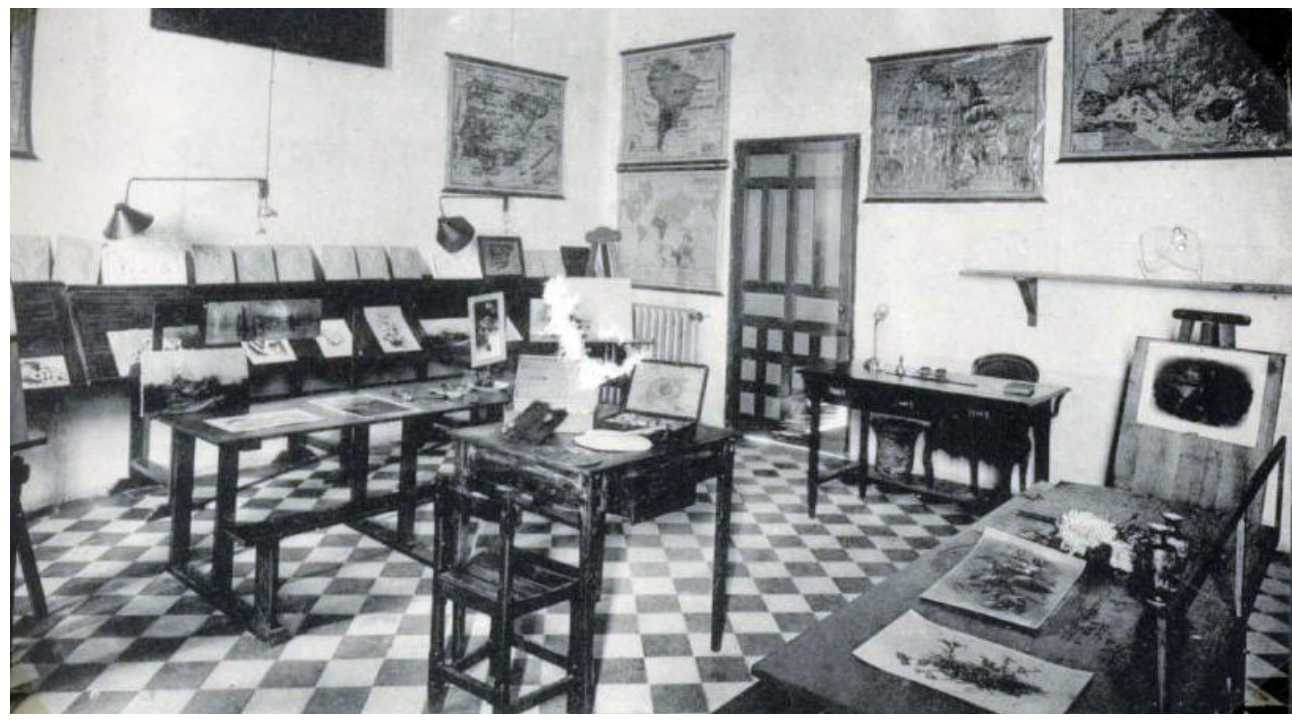

Fotografía 8. Clase de pintura y dibujo en el Real Colegio de Nuestra Señora de los Remedios de Toledo (1959). ${ }^{67}$

Los mapas regionales se pueden observar exclusivamente en centros cuya titularidad no es religiosa. El caso más llamativo es el de Galicia. El colegio Fingoy, un centro privado de la ciudad de Lugo fundado en el año 1950 por el filántropo Antonio Fernández López,68 tenía en una de sus aulas un mapa físico de la región que destaca por sus considerables dimensiones, ocupando un espacio predominante en un lateral del aula, apoyado en la pared (fotografía 9). ${ }^{69}$ La fotografía, por el ángulo mostrado y la baja calidad en el enfoque, que refleja movimiento en su ejecución, sumado a la ausencia de algún tipo de sellado o firma profesional en el reverso, indica que se trataría de una toma realizada por un profesional amateur, en este caso seguramente por la propia estudiante que firma la memoria de prácticas.

\footnotetext{
${ }^{67}$ Laín, El colegio Nuestra Señora de los Remedios, s.p.

${ }^{68}$ Xosé Ramón Cando Vázquez, Carmen Cortizas Rodríguez e Isabel Rivas Barrós, «La experiencia del colegio Fingoy», Revista de Innovación Educativa 0 (1991): 95.

${ }_{69}$ Cabe destacar que en este colegio las fotografías que muestran el aula y otras dependencias no tienen simbología patriótica. El aula está presidida por un crucifijo y el comedor por una pintura mural de un paisaje.
} 


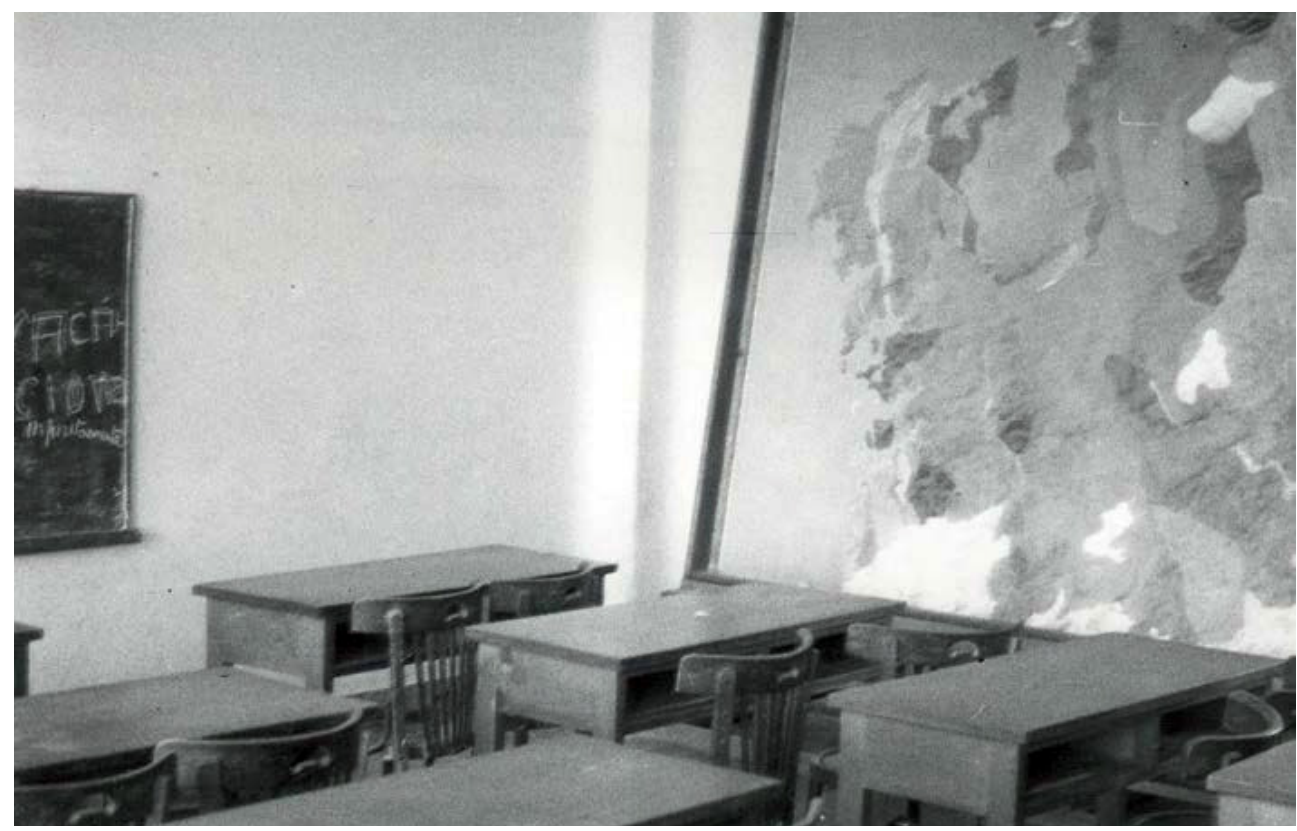

Fotografía 9. Mapa regional de Galicia en un aula del colegio Fingoy en Lugo (1959).70

Fue diseñado por el arquitecto gallego Manuel Gómez Roldán, ${ }^{71}$ y su primer director fue Ricardo Carballo Calero. Su equipo docente contó con figuras como el escritor y político Xosé Luís Méndez Ferrín, quien posteriormente sería presidente de la Real Academia Galega,72 Bernardino Graña, primer presidente de la Asociación de Escritores en Lingua Galega, ${ }^{73}$ y Arcadio López Casanova, poeta exponente de la cultura gallega; ${ }^{74}$ que dan cuenta del marcado carácter galleguista de este centro.

\footnotetext{
${ }^{70}$ María García de la Mata, «El colegio Fingoy en Lugo», 1959, pp. 52, 448, Fondo Romero Marín (FRM). Museo de Historia de la Educación Manuel Bartolomé Cossío, UCM.

71 Víctor F. Freixanes, «Manuel Gómez Román», La Voz de Galicia, 23 de noviembre de 2014.

72 Agencia EFE, «Méndez Ferrín, elegido por mayoría nuevo presidente de la Real Academia Galega», La Voz de Galicia, 23 de enero de 2010.

${ }^{73}$ Asociación de Escritoras e Escritores en Lingua Galega (AELG), "Consellos directivos», AELG, http://www.aelg.gal/consellos-directivos (consultado el 31-05-2018).

${ }^{74}$ Xesús Alonso Montero, "Arcadio López-Casanova», Thélème. Revista Complutense de Estudios Franceses 17 (2002): 104.
} 
La pedagogía propugnada por esta institución estuvo profundamente ligada a los ideales de la Institución Libre de Enseñanza y a los principios educativos del pedagogo francés Célestin Freinet. En definitiva, el recorrido, los profesionales y las ideas que sustentaron este centro dan cuenta de una marcada defensa de la cultura gallega, que justificaría la presencia del amplio mapa regional antes expuesto.

Otro de los casos se encuentra en el País Vasco. Concretamente en la provincia de Vizcaya, en la localidad costera de Bermeo. En este caso, se halla en la escuela nacional, en la cual se puede observar, en una de sus clases, una fotografía profesional, por su encuadre y perspectiva.

En ella se ven dos mapas que ponen de relieve la importancia de la cultura del marco provincial y local en este centro. Esta impronta aparece reflejada con un plano local de la ciudad de Bermeo dibujado sobre la pizarra, y un mapa físico provincial de Vizcaya a la derecha, sobre la pared frontal del aula (fotografía 10).

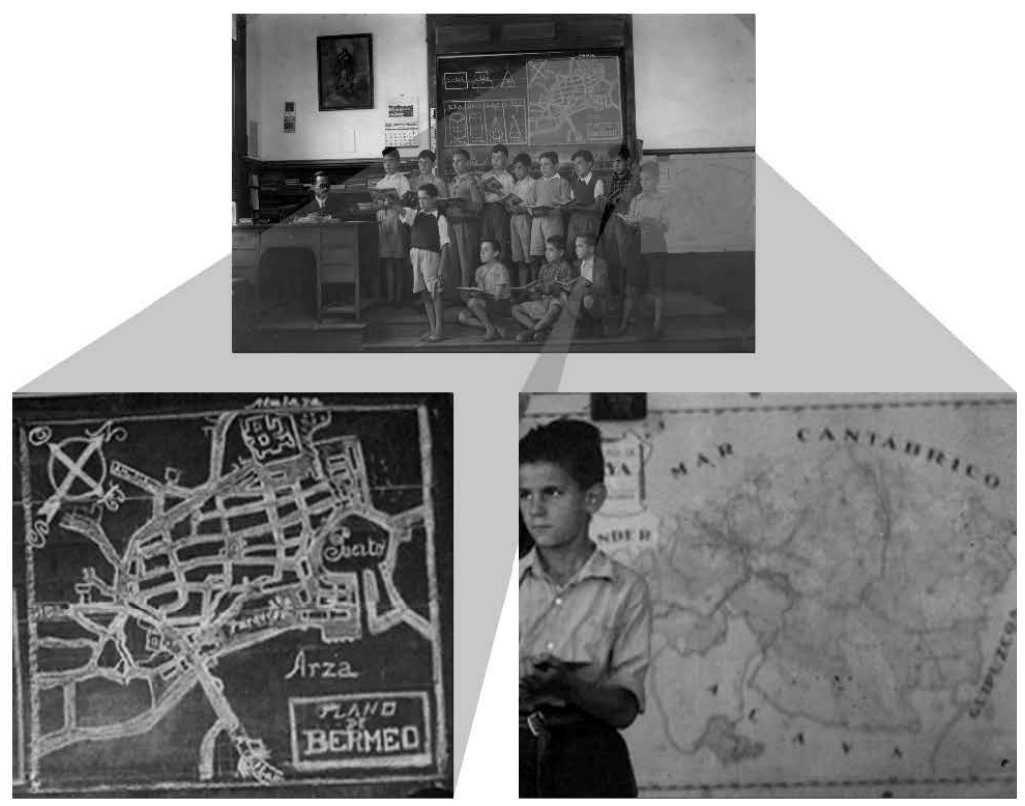

Fotografía 10. Detalles del plano local de la ciudad de Bermeo y del mapa físico provincial de Vizcaya en el aula de una escuela de Bermeo (Vizcaya, 1955). ${ }^{75}$

75 Dolores Albizua Zabala, «Bermeo», 1955, pp. 146, 303, Fondo Romero Marín (FRM), Museo de Historia de la Educación Manuel Bartolomé Cossío, UCM. 
La memoria a la que pertenece la fotografía, realizada por la estudiante Dolores Albizua Zabala, es en sí misma un ensalzamiento y defensa de la cultura local. En sus páginas se puede observar un escudo local pintado con todo detalle, y apartados que ponen de relieve el hecho diferencial de la personalidad bermeana.

Cabe destacar que esta localidad fue la primera en la cual el Partido Nacionalista Vasco alcanzó la mayoría en unas elecciones municipales, en el año 1901.76 Desde entonces, se mostró como uno de los principales baluartes del nacionalismo vasco en la provincia vizcaína, mostrando un ferviente apoyo a la consecución del Estatuto de Estella durante el periodo republicano. ${ }^{77}$

Otros símbolos que representan identidades y tradiciones son, por ejemplo, los escudos. Al margen de aquellos nacionales, las fachadas de algunos centros también se revistieron con la heráldica regional y local.

El primer caso es el de Castilla. Tras la herencia que recibió Fernando III del Reino de León en 1280, quiso incorporar a éste en la heráldica castellana. Desde entonces, el escudo cuartelado de blancos y gules, aunando al castillo y al león ha tenido una trayectoria constante, con sus símbolos presentes en todos los escudos y banderas nacionales hasta la actualidad. ${ }^{78}$

También llegó a las fachadas. Así lo demuestra una escuela de niñas de la localidad guadalajareña de Molina de Aragón (fotografía 11). Presidiendo la puerta principal, en la parte superior de la fachada, se encuentra un escudo ondeado y coronado de la casa de Castilla. En la misma fachada, en el cuarto superior derecho, aparece otro escudo, sin corona, con un cuartelado y tonos similares, si bien no se puede distinguir exactamente su contenido. Podría tratarse de otro escudo similar, pero cabe también la hipótesis de que sea el escudo de armas del infante Don Manuel de Castilla, en cuyos cuartelados gules apareció un puño

\footnotetext{
${ }^{76}$ Ander Delgado Cendagortagalarza, «El origen del nacionalismo en Bermeo. La estrategia del PNV en el distrito electoral de Gernika (Bizkaia), 1898-1910», Historia Contemporánea 21 (2000): 595.

77 Francisco Manuel Vargas Alonso, Bermeo y la Guerra Civil. La batalla del Sollube (Donostia-San Sebastián: Eusko Ikaskuntza, 2007), 33-34.

78 Faustino Menéndez Pidal, El escudo de España (Madrid: Real Academia Matritense de Heráldica y Genealogía, 2004), 77; Antonio Herrera Casado y Antonio Ortiz García, Heráldica municipal de Guadalajara (Guadalajara: AACHE Ediciones, 2001), 45.
} 
alado. ${ }^{79}$ Cualquiera que fuera la hipótesis, se trataría de un símbolo de naturaleza castellana, una identidad que, como se ha señalado al inicio del presente estudio, fue exaltada por el Régimen.

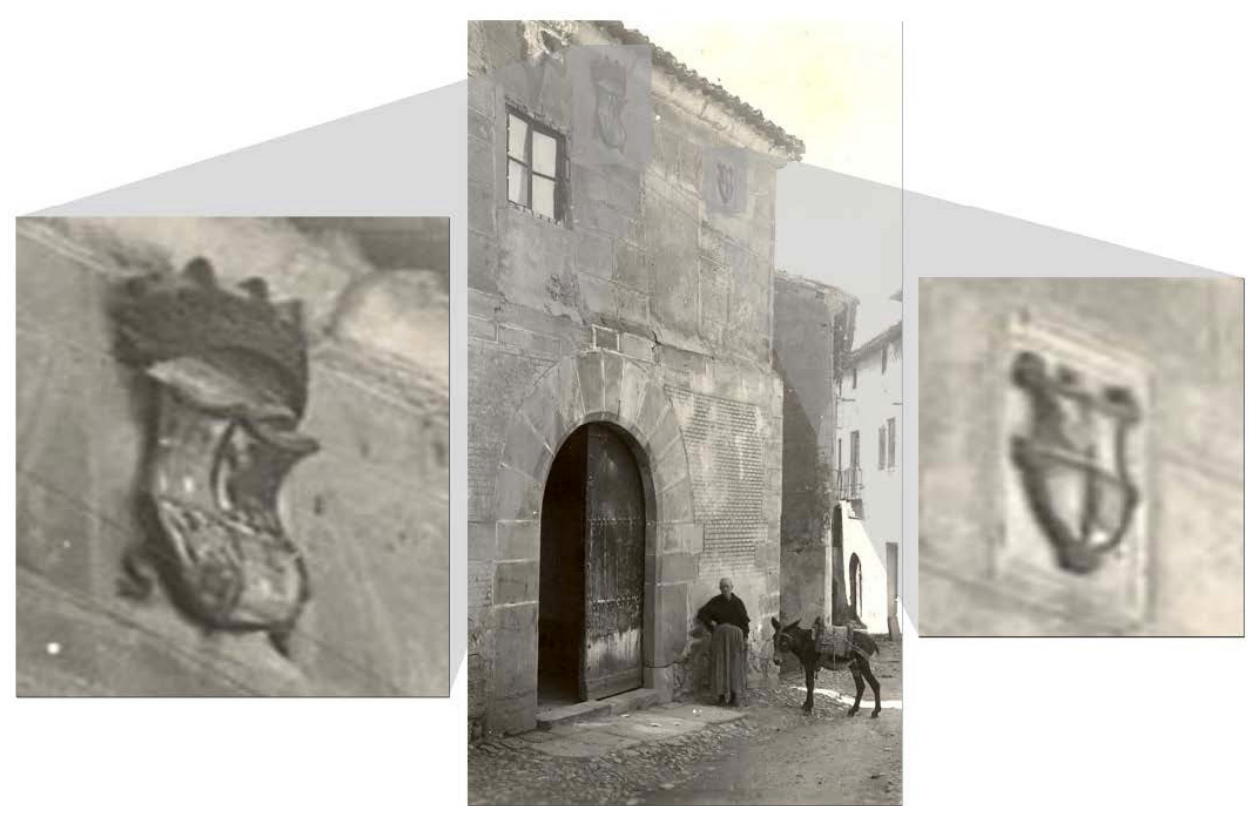

Fotografía 11. Fachada de una escuela de niñas en Molina de Aragón (Guadalajara, 1955). ${ }^{80}$

Otro caso de heráldica no nacional se encuentra nuevamente en Bermeo, si bien en esta ocasión en una escuela infantil de titularidad religiosa, financiada por la caja de ahorros municipal de Bilbao. Su fachada principal se encuentra presidida por el escudo municipal de la capital de Vizcaya (fotografía 12), ${ }^{81}$ lo que podría justificarse por el patrocinio económico que sustentó el centro.

\footnotetext{
${ }^{79}$ Herrera y Ortiz, Heráldica municipal de Guadalajara, 45.

${ }^{80}$ María del Carmen Romero Villanueva, «Monografía pedagógica de la Ciudad de Molina», 1955, pp. 90, 245, Fondo Romero Marín (FRM), Museo de Historia de la Educación Manuel Bartolomé Cossío, UCM.

${ }^{81}$ Los escudos de Bilbao y Bermeo tienen como rasgo común la presencia de dos lobos, que en caso del bilbaíno aparecen en el lateral derecho uno sobre otro, mientras que en el segundo caso lo hacen en faja u horizontalmente. Ambos Reflejan a la familia que fundó las dos urbes, los Haro. Bilbao fue fundada por Diego López V de Haro y Bermeo por López Díaz II de Haro.
} 


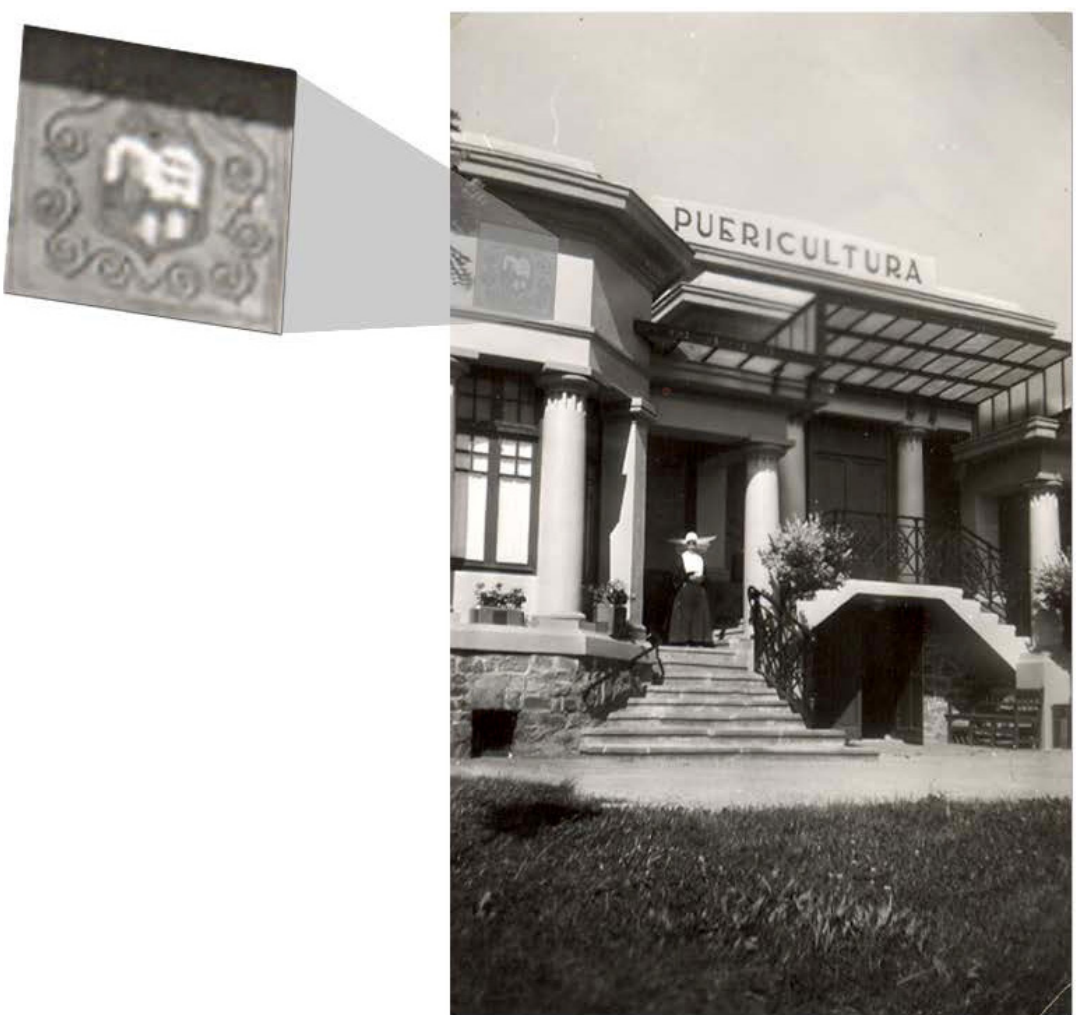

Fotografía 12. Fachada de la casa de los niños de Bermeo (Vizcaya, 1955). ${ }^{82}$

Finalmente, otros elementos que reflejan aspectos identitarios diferenciales serían los objetos y celebraciones folclóricas. Nuevamente, el colegio Fingoy de Lugo muestra elementos identitarios que formaban parte, en palabras de la estudiante que redactó la memoria, de las clases de folclore regional. ${ }^{83}$ Se trata de unas gaitas realizadas en los talleres de carpintería (fotografía 13).

\footnotetext{
82 Albizua, Bermeo, 127.

${ }^{83}$ García, El colegio Fingoy en Lugo, 24.
} 


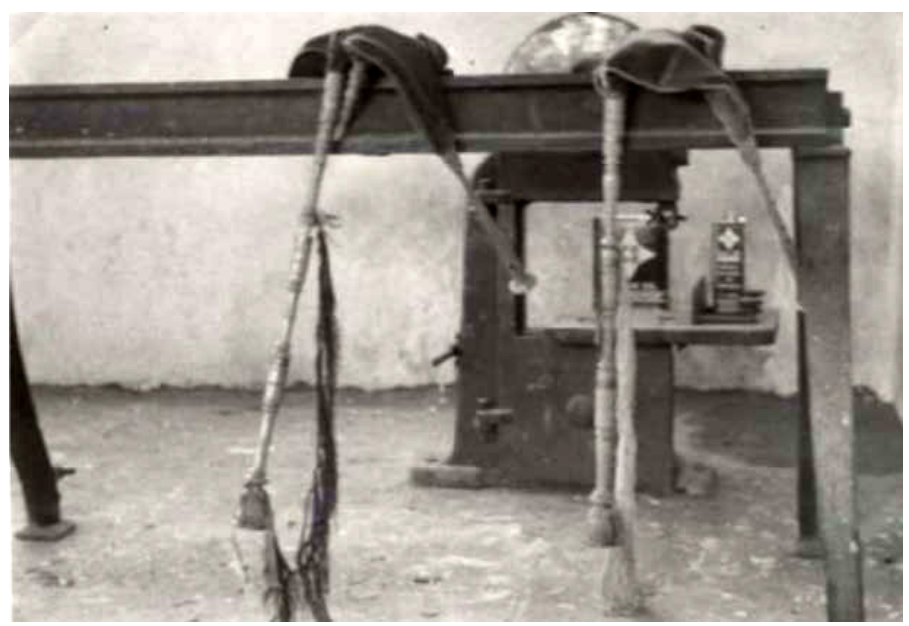

Fotografía 13. Gaitas en taller de carpintería (Lugo, 1955). ${ }^{84}$

Finalmente, los eventos sociales en los pueblos mostraban también la vestimenta regional. En las memorias seleccionadas, se observan en las localidades castellanas de Aforados de Moneo (Burgos) y Berlanga de Duero (Soria) (fotografías 3 y 14).

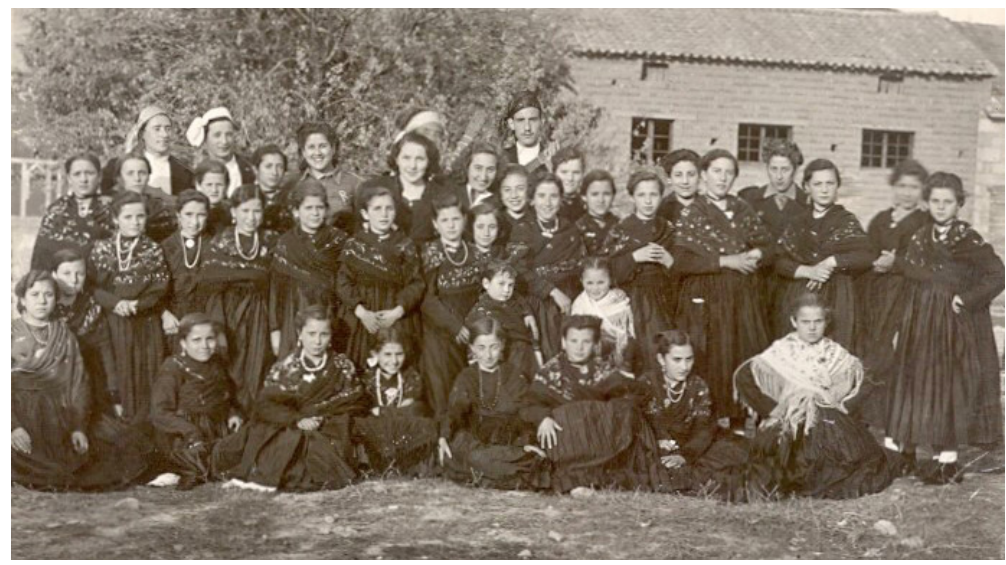

Fotografía 14. Jóvenes vestidas con el traje regional acompañadas de un chico que sostiene una guitarra en una escuela graduada de Berlanga de Duero (Soria, 1954). ${ }^{85}$

${ }^{84}$ García, El colegio Fingoy en Lugo, 24.

${ }_{85}$ Andrea Marcos Ramos, «Problemas pedagógicos de Berlanga de Duero», 1954, pp. 69, 233, Fondo Romero Marín (FRM), Museo de Historia de la Educación Manuel Bartolomé Cossío, UCM. 


\section{Sexo del alumnado}

La tercera de las variables a considerar hace referencia al modo en que alumnos y alumnas se vinculaban a la simbología patriótica. Considerando aquellas fotografías en las que las aulas, dependencias o exteriores de los centros educativos donde el alumnado estaba en contacto con estos símbolos, en algunos casos se puede observar cómo la forma en la cual se relacionaban con los mismos distaba considerablemente.

En las aulas, en la ciudad de Madrid se ha encontrado un caso, relativo a un centro encargado de niños y niñas abandonadas y/o delincuentes gestionado por la Iglesia católica, en el cual las diferencias son evidentes. Mientras los chicos se encuentran en talleres de sastrería y carpintería presididos por el retrato del dictador, las chicas se encuentran en talleres de labores, confección o cocina con referentes exclusivamente católicos (fotografía 15).
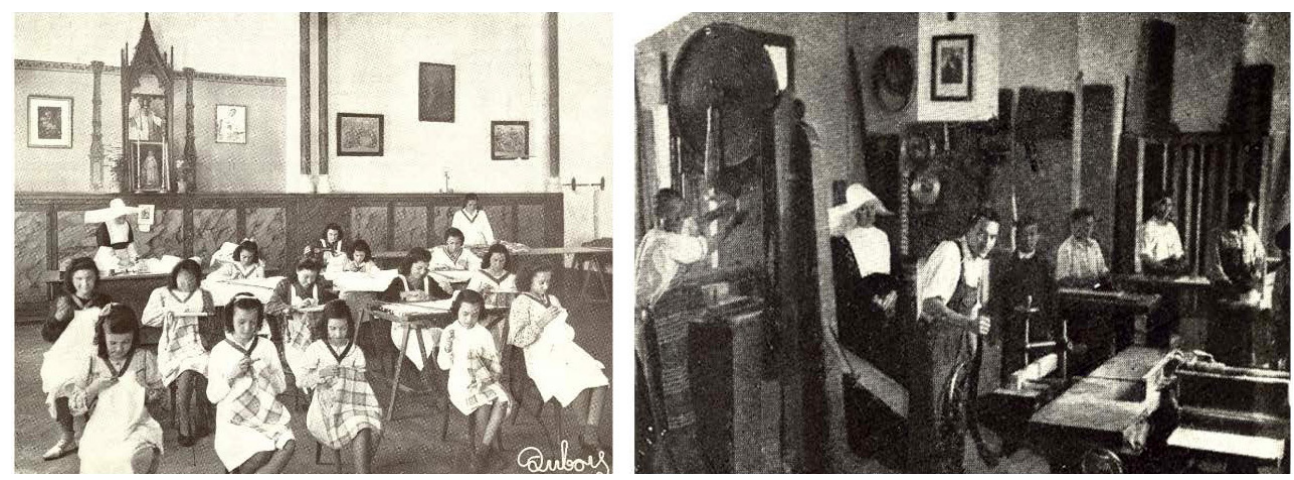

Fotografía 15. Comparación de labores realizadas por chicos y chicas en centros de gestión religiosa encargados de atender a jóvenes abandonados y/o delincuentes (Madrid, 1956).86

Las mencionadas diferencias ahondan, como señaló Carmen Agulló, en la idea de que la mujer debe jugar un papel asistencial, relegada al marco doméstico, mientras que el hombre adquiere un rol de autoridad y protección. ${ }^{87}$ Estas ideas se repiten a lo largo de las fotografías analizadas, destacando dos casos concretos. En primer lugar, en el coto escolar

\footnotetext{
${ }_{86}$ María Socorro Martín, «Estudio del fenómeno educativo en el niño abandonado y delincuente», 1956, pp. 42, 55, 205, Fondo Romero Marín (FRM), Museo de Historia de la Educación Manuel Bartolomé Cossío, UCM.
}

${ }^{87}$ Agulló, «Mujeres para Dios», 19. 
Virgen Milagrosa del municipio serrano de Guadarrama (Madrid), donde se puede observar un conjunto de labores confeccionadas por las niñas que rodean todo tipo de simbología nacionalcatólica (retratos del dictador y del líder de la Falange, el crucifijo, estatuas de una virgen y del Sagrado Corazón de Jesús, e incluso una bandera nacional), en una suerte de altar de la patria (fotografía 16).

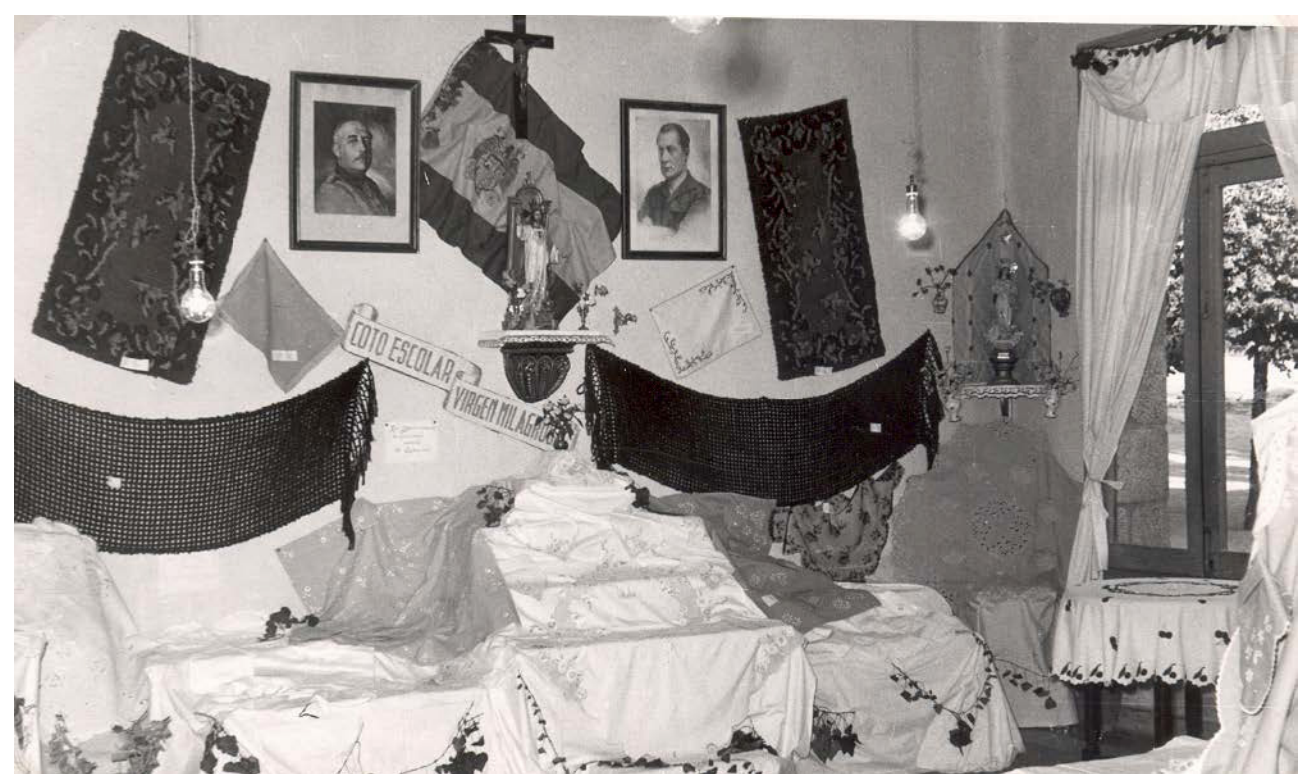

Fotografía 16. Sala del coto escolar Virgen Milagrosa, en Guadarrama (Madrid, 1958). ${ }^{88}$

Por su parte, las prácticas patrióticas vinculadas al sexo masculino aparecen en las actividades físicas, en ocasiones acompañadas de eslóganes como el caso de un colegio de Medina del Campo, que relaciona el fascismo con la pureza del alma vinculada a la gimnasia (fotografía 17).

\footnotetext{
${ }^{88}$ Manuela Redondo Fraguas, «Guadarrama: Su aspecto pedagógico», 1958, pp. 32, 664, Fondo Romero Marín (FRM), Museo de Historia de la Educación Manuel Bartolomé Cossío, UCM.
} 

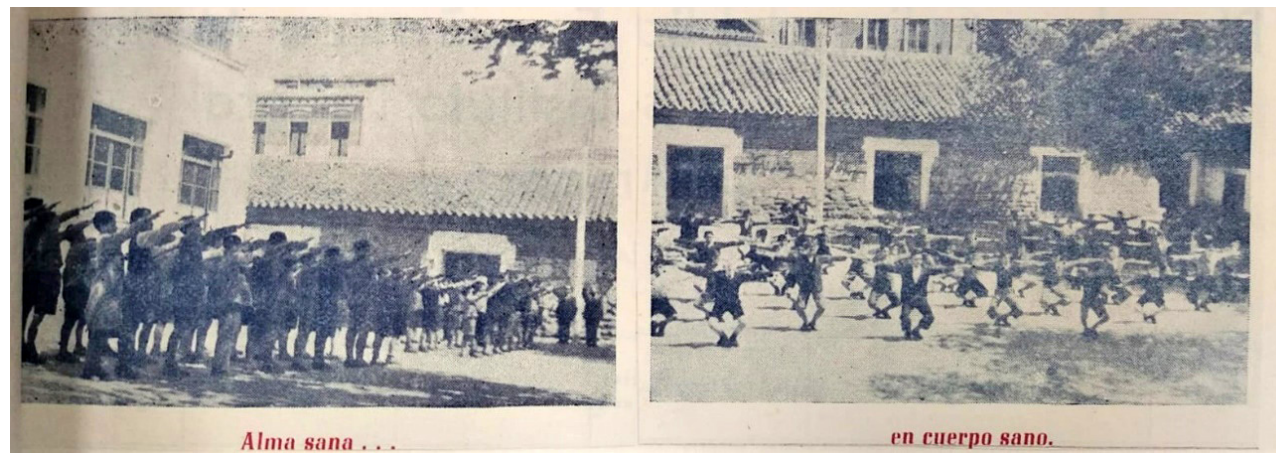

Fotografía 17. Niños realizando el saludo fascista y educación física en un colegio de Medina del Campo (Valladolid, 1952) ${ }^{89}$

En la mayoría de los casos registrados en las memorias analizadas, se detecta que, en el momento en que se dan actividades por separado, hay una tendencia a vincular el sexo femenino con la simbología religiosa mientras el sexo masculino se liga a símbolos patrióticos. De esta forma, la mujer tendría que poseer la «resignación cristiana» de las labores domésticas y asistenciales con el hogar y la familia, entendiendo así su servicio a la patria, vinculada a figuras religiosas como las vírgenes. En cambio, los hombres estarían ligados en mayor medida a los referentes políticos de la Dictadura, símbolos de la autoridad y la protección de la patria, el hogar y la familia.

\section{CONSIDERACIONES FINALES}

La simbología del nacionalcatolicismo estuvo presente en la enseñanza española de forma generalizada, si bien la combinación de ambas caras del Régimen estuvo más representada en los centros cuya titularidad no dependía de la Iglesia católica. En aquellos centros regentados por las órdenes y congregaciones religiosas, se muestra una tendencia hacia la simbología propia.

Sin embargo, estos símbolos tuvieron que convivir en algunas ocasiones con representaciones y elementos regionales, sobre todo en Galicia

\footnotetext{
89 Albertina Gómez Álvarez, «Problemas educativos de Medina del Campo», 1952, pp. 40b, 380, Fondo Romero Marín (FRM), Museo de Historia de la Educación Manuel Bartolomé Cossío, UCM.
} 
y el País Vasco. Dada la naturaleza de la muestra, la propia limitación del fondo con las memorias de Cataluña ha permitido extraer únicamente elementos que permiten obtener un primer acercamiento a la realidad de la representación simbólica de las escuelas de esta región, la cual desarrolló un nacionalismo acusado anterior a la Dictadura.

Por otro lado, la perspectiva del género contribuye una vez más a comprender la realidad educativa del Régimen, constatando las diferencias en las actividades desempeñadas por niños y niñas en los centros, y atestiguando una vinculación con la simbología con ideales y referentes claramente diferenciados.

Respecto a las propias fuentes, las memorias de prácticas se han mostrado nuevamente como un instrumento de gran valor histórico-educativo, si bien cuentan con limitaciones. A este respecto, hay que retomar su carácter subjetivo, que deriva en un condicionamiento directo e indirecto e impide una generalización de las realidades educativas analizadas por los estudiantes. Directo, porque pese a que nos permiten conocer de forma parcial la realidad escolar de un contexto determinado, se encuentran condicionadas por la predisposición, ideología y formación de los propios autores. Asimismo, se tratan de fuentes condicionadas indirectamente porque fueron elaboradas por estudiantes que iban a ser evaluados por un determinado profesor. Este aspecto no resulta una excepción, pues la subjetividad, como elemento inherente a la condición humana, es también aplicable a otros materiales como los cuadernos escolares, los exámenes, o la legislación educativa —entre otras fuentes-, y como tal debe ser historiada.

Además, al tratarse de una fuente poliédrica, que incluye diferentes recursos de investigación, permite entrever los diferentes niveles de prescripción o culturas que guían el funcionamiento de las instituciones educativas, como la cultura práctica, académica o política. Gracias a ello, se pueden observar algunos de los cambios y continuidades que existen en momentos de ruptura política, como fue el caso de la Dictadura franquista.

Para finalizar, se concluye con la idea de que las fotografías son fuentes poliédricas cuya interpretación nunca es definitiva. Como fuente histórica en general, y las analizadas en la presente investigación en particular, tienen tantas posibilidades y perspectivas como miradas las observen. 


\section{Nota sobre el autor}

CARlos SAnz Simón es graduado en Pedagogía (2015) y Máster en Investigación en Educación (2016) por la Universidad Complutense de Madrid. En esta institución actualmente cursa los estudios de Doctorado en Educación como contratado predoctoral en el Departamento de Estudios Educativos. Forma parte del grupo de investigación consolidado Claves históricas y comparadas de la Educación. Género e identidades (CLAVES, UCM) y pertenece al consejo editorial de la revista Cabás. Además, es miembro de la Sociedad Española de Historia de la Educación (SEDHE) y de la Sociedad Española para el Estudio del Patrimonio Histórico-Educativo (SEPHE). Actualmente desarrolla su tesis doctoral sobre la construcción de la identidad nacional en las escuelas primarias de España e Italia entre 1os años treinta y cincuenta del siglo XX. Sus principales líneas de investigación se centran en el estudio del nacionalismo en la escuela, la simbología patriótica, los textos escolares y las memorias de prácticas.

\section{REFERENCIAS}

Agulló Díaz, Ma del Carmen. «Mujeres para Dios, para la Patria y para el hogar». En Mujeres y educación en España. VI Coloquio de Historia de la Educación, 17-26. Santiago de Compostela: Departamento de Teoría e Historia de la Educación, 1990.

Álvarez Junco, José. Dioses útiles. Naciones y nacionalismos. Barcelona: Galaxia Gutenberg, 2016.

Anderson, Benedict. Comunidades imaginadas. Reflexiones sobre el origen y la difusión del nacionalismo. México D. F.: Fondo de Cultura Económica, 1993.

Barceló Bauzá, Gabriel, Francisca Comas Rubí y Bernat Sureda García. «Abriendo la caja negra: la escuela pública española de postguerra». Revista de Educación 371 (2016): 61-82. http://dx.doi.org/10.4438/1988-592XRE-2015-371-308

Beas Miranda, Miguel. «El orden del tiempo y los ritmos escolares». En Historia ilustrada de la escuela en España. Dos siglos de perspectiva histórica, dirigido por Agustín Escolano Benito, 309-330. Madrid: Fundación Germán Sánchez Ruipérez, 2006.

Beramendi González, Justo. «Nacionalismos, regionalismos y autonomía en la Segunda República». Pasado y Memoria 2 (2003): 1-77. https://rua.ua.es/dspace/bitstream/10045/713/1/Beramendi\%20Gonzalez-Nacionalismos.pdf 
Blasco Herranz, Inmaculada. Mujeres, hombres y catolicismo en la España contemporánea. Nuevas visiones desde la Historia. Valencia: Tirant Humanidades, 2018.

Boyd, Carolyn P. Historia patria. Patria, historia e identidad nacional en España: 1875-1975. Barcelona: Pomares-Corredor, 1997.

Box Varela, Zira. «La fundación de un régimen. La construcción simbólica del franquismo». PhD diss., Universidad Complutense de Madrid, 2008.

Burke, Peter. Visto y no visto: el uso de la imagen como documento histórico. Barcelona: Crítica, 2005.

Canales Serrano, Antonio Francisco. «El robo de la memoria. Sobre el lugar del franquismo en la historiografía católico-catalanista». Ayer 59 (2005): 259280.

Cando Vázquez, Xosé Ramón, Carmen Cortizas Rodríguez e Isabel Rivas Barrós. «La experiencia del colegio Fingoy». Revista de Innovación Educativa 0 (1991): 95-105.

Casanova Ruiz, Julián. República y guerra civil. Volumen 8. Barcelona: Marcial Pons, 2014.

Castro Berrojo, Luis. Capital de la cruzada. Burgos durante la Guerra Civil. Barcelona: Crítica, 2006.

Comas Rubí, Francisca. «Fotografía i historia de l'educació». Educació i Història: Revista d'Història de l'Educació 15 (2010): 11-17. http://dx.doi. org/10.2436/20.3009.01.51

Delgado Cendagortagalarza, Ander. «El origen del nacionalismo en Bermeo. La estrategia del PNV en el distrito electoral de Gernika (Bizkaia), 1898-1910». Historia Contemporánea 21 (2000): 595-626.

Domínguez García, Javier. Memorias del futuro. Ideología y ficción en el símbolo de Santiago Apóstol. Madrid: Iberoamericana - Vervuert, 2008.

Domínguez Méndez, Rubén. «El Estatuto non nato de Castilla y León en la prensa vallisoletana durante 1936». Aposta. Revista de Ciencias Sociales 60 (2014): 1-24.

Escolano Benito, Agustín. «Las culturas escolares en el último medio siglo». En Historia ilustrada de la escuela en España. Dos siglos de perspectiva histórica, dirigido por Agustín Escolano Benito, 267-288. Madrid: Fundación Germán Sánchez Ruipérez, 2006.

Febo, Giuliana di. La Santa de la Raza. Teresa de Ávila, un culto barroco en la España franquista (1937-1962). Barcelona: Icaria, 1988.

Fusi Aizpurúa, Juan Pablo. España. La evolución de la identidad nacional. Madrid: Temas de Hoy, 2000.

Gervilla Castillo, Enrique. «La escuela del nacionalcatolicismo. Cercanía cronológica y distanciamiento axiológico». Bordón. Revista de Pedagogía 58, no. 4-5 (2006): 537-538. 
Guibernau, Montserrat. Catalan Nationalism. Francoism, transition and democracy. Londres: Routledge, 2004.

Harley, John Brian. The new nature of maps: essays in the history of cartography. Baltimore: The John Hopkins University Press, 2001.

Herrera Casado, Antonio y Antonio Ortiz García. Heráldica municipal de Guadalajara. Guadalajara: AACHE Ediciones, 2001.

López Martín, Ramón. "El utillaje escolar en la segunda mitad del siglo XX». En Historia ilustrada de la escuela en España. Dos siglos de perspectiva histórica, dirigido por Agustín Escolano Benito, 425-448. Madrid: Fundación Germán Sánchez Ruipérez, 2006.

Mainer Baqué, Juan. La forja de un campo profesional. Pedagogía y Didáctica de las Ciencias Sociales en España (1900-1970). Madrid: Consejo Superior de Investigaciones Científicas, 2009.

Mainer, José Carlos. "La imagen de Castilla en el fascismo español». En Historia de la nación y del nacionalismo español, dirigido por Antonio Morales, Juan Pablo Fusi y Andrés de Blas, 855-873. Barcelona: Galaxia Gutenberg, 2013.

Maza Zorrilla, Elena. «El mito de Isabel de Castilla como elemento de legitimidad política en el franquismo». Historia y política 31 (2014): 167-192.

Meda, Juri. Mezzi di educazione di massa. Saggi di storia della cultura materiale della scuola tra XIX e XX secolo. Milán: FrancoAngeli, 2016.

Menéndez Pidal, Faustino. El escudo de España. Madrid: Real Academia Matritense de Heráldica y Genealogía, 2004.

Montero, Xesús Alonso. "Arcadio López-Casanova». Thélème. Revista Complutense de Estudios Franceses 17 (2002): 103-107.

Moreno Luzón, Javier y Xosé Manoel Núñez Seixas. Los colores de la patria. Símbolos nacionales en la España contemporánea. Madrid: Tecnos, 2017.

Moreno Martínez, Pedro Luis. «Imágenes e historia de la educación popular: representaciones fotográficas de las Misiones Pedagógicas en la Región de Murcia». Historia y Memoria de la Educación 5 (2017): 73-115. http://dx.doi. org/10.5944/hme.5.2017.16799

Muñoz Mendoza, Jordi. La construcción política de la identidad española: ¿del nacionalcatolicismo al patriotismo democrático? Madrid: Centro de Investigaciones Sociológicas, 2012.

Núñez Seixas, Xosé Manoel. «La región y lo local en el primer franquismo». En Imaginarios y representaciones de España durante el franquismo, editado por Stéphane Michonneau y Xosé M. Núñez Seixas, 127-154. Madrid: Casa de Velázquez, 2014.

Ostolaza Esnal, Maitane. «Género, religión y educación en la España contemporánea: Estado de la cuestión y perspectivas historiográficas». En Mujeres, hombres y catolicismo en la España contemporánea. Nuevas visiones desde la 
historia, editado por Inmaculada Blasco Herranz, 48-68. Valencia: Tirant Humanidades, 2018.

Panofsky, Edwin. Estudios sobre iconología. Madrid: Alianza Editorial, 1972.

Poveda Sanz, María y Teresa Rabazas Romero. «El Fondo Romero Marín del Museo "Manuel B. Cossío. Análisis de las memorias de prácticas de Pedagogía». En III Foro Ibérico de Museísmo Pedagógico y V Jornadas Científicas de la Sociedad Española para el Estudio del Patrimonio Histórico Educativo, 323-336, 2012. http://congresos.um.es/fimupesephe/fimupesephe2012/schedConf/presentations

Pozo Andrés, María del Mar del. «Imágenes e historia de la educación: construcción, reconstrucción y representación de las prácticas escolares en el aula». Historia de la Educación. Revista interuniversitaria 25 (2006): 291315.

Pozo Andrés, María del Mar del. Currículum e identidad nacional. Regeneracionismos, nacionalismos y escuela pública (1890-1939). Madrid: Biblioteca Nueva, 2000.

Pozo Andrés, María del Mar del y Teresa Rabazas Romero. «Políticas educativas y prácticas escolares: la aplicación de la Ley de Enseñanza Primaria de 1945 en las aulas». Bordón. Revista de Pedagogía 65, no. 4 (2013): 119-133. http://dx.doi.org/10.13042/Bordon.2013.65408

Pozo Andrés, María del Mar del y Teresa Rabazas Romero. «Las imágenes fotográficas como fuente para el estudio de la cultura escolar: precisiones conceptuales y metodológicas». Revista de Ciencias de la Educación: Órgano del Instituto Calasanz de Ciencias de la Educación 231-232 (2012): 401-414.

Pozo Andrés, María del Mar del y Teresa Rabazas Romero. «Imatges fotogràfiques i cultura escolar en el franquisme: una exploració de l'arxiu etnogràfic». Educaciói Història 15(2010): 165-194.http://dx.doi.org/10.2436/20.3009.01.59

Puelles Benítez, Manuel de. Política, legislación y educación. Madrid: UNED, 2017.

Queralt del Hierro, María Pilar. Tal como éramos. Las niñas que fuimos y... las mujeres que somos. Madrid: EDAF, 2016.

Rabazas Romero, Teresa, Sara Ramos Zamora y Carmen Colmenar Orzaes. «Fotografía y representación de la escuela privada madrileña en el franquismo. Entre la propaganda y el relato». Historia y Memoria de la Educación 8 (2018): 397-448. https://doi.org/10.5944/hme.8.2018.19342

Rabazas Romero, Teresa y Sara Ramos Zamora. «The School Child. Two images of a pedagogical model in Madrid, 1960s». History of Education \& Children's Literature 8, no. 1 (2018): 305-326.

Rabazas Romero, Teresa y Sara Ramos Zamora. «Museografía y docencia en el Museo/Laboratorio de Historia de la Educación Manuel Bartolomé Cossío». En Los Museos Pedagógicos en España: entre la memoria y la creatividad, 
P. Álvarez Domínguez, 163-172. Gijón y Sevilla: TREA Ediciones y Ediciones de la Universidad de Sevilla, 2016.

Ruiz Berrio, Julio. «Manuel Bartolomé Cossío y los comienzos de los estudios de Pedagogía en la Universidad». En Pedagogía y Educación ante el siglo $X X I$, coordinado por Julio Ruiz Berrio, 117-141. Madrid: Departamento de Teoría e Historia de la Educación, 2005.

Sanz Simón, Carlos, y Teresa Rabazas Romero. «La identidad nacional en los manuales escolares durante la Segunda República Española». Bordón. Revista de Pedagogía 69, no. 2 (2017): 131-146. https://doi.org/10.13042/Bordon.2017.50578

Serrano, Carlos. El nacimiento de Carmen. Símbolos, mitos, nación. Madrid: Taurus, 1999.

Sonlleva Velasco, Miriam, Carlos Sanz Simón y Luis Mariano Torrego Egido. «Sociedad y educación en la posguerra (1939-1953). Una mirada desde las imágenes de las memorias de prácticas de los primeros pedagogos instruidos en el franquismo». Historia Social y de la Educación 7, no. 1 (2018): 2654. http://dx.doi.org/10.17583/hse.2018.2903

Sonlleva Velasco, Miriam, Carlos Sanz Simón y Luis Mariano Torrego Egido. «El retrato de Franco, el de José Antonio y el crucifijo. Construcción de la identidad nacional en los escolares de posguerra». El Futuro del Pasado. Revista electrónica de Historia 9 (2018): 331-363. https://doi.org/10.14516/10.14516/ fdp.2018.009.001.012

Storm, Eric. «Una España más española. La influencia del turismo en la imagen nacional». En Ser españoles. Imaginarios nacionalistas en el siglo XX, eds. Javier Moreno Luzón y Xosé M. Núñez Seixas, 530-559. Barcelona: RBA, 2013.

Varela Ortega, José. «La mirada del otro. La imagen de España en el extranjero: Introducción y esquema para la historia de un estereotipo». En Historia de la nación y del nacionalismo español, dirigido por Antonio Morales Moya, Juan Pablo Fusi Aizpurúa y Andrés de Blas Guerrero, 1089-1112. Barcelona: Galaxia Gutenberg, 2013.

Vargas Alonso, Francisco Manuel. Bermeo y la Guerra Civil. La batalla del Sollube. Donostia-San Sebastián: Eusko Ikaskuntza, 2007.

Viñao Frago, Antonio. Escuela para todos. Educación y modernidad en la España del siglo XX. Madrid: Marcial Pons, 2004. 